The Federal Reserve BanK of Kansas City Research Working Papers

Health Care Reform or Labor Market Reform? A Quantitative Analysis of the Affordable Care Act

Makoto Nakajima and Didem Tüzemen

September 2015; Revised March 2017

RWP 15-10 


\title{
Health-Care Reform or Labor Market Reform? A Quantitative Analysis of the Affordable Care Act*
}

\author{
Makoto Nakajima ${ }^{\dagger} \quad$ Didem Tüzemen ${ }^{\ddagger}$
}

March 23, 2017

\begin{abstract}
An equilibrium model with firm and worker heterogeneity is constructed to analyze labor market implications of the Affordable Care Act (ACA). Our model indicates that the ACA lowers the uninsured rate from 22.6 to 5.4 percent, with a moderate welfare gain due to increased redistribution through health insurance subsidies and Medicaid expansion. Because of the weakened link between full-time employment and access to insurance, 2.1 million more part-time jobs are created at the expense of 1.6 million full-time jobs. The predicted negative effect on total hours ( 0.36 percent) is smaller than other estimates, partly due to the general equilibrium effect.

Keywords: health insurance, health-care reform, Affordable Care Act, labor market, heterogeneous agents

JEL Classification: E24, E65, I13, J20
\end{abstract}

\footnotetext{
${ }^{*}$ We thank seminar and conference participants at the 2014 SED Annual Meeting in Toronto, the 2014 SAET Annual Meeting in Tokyo, the ASU Conference on Health Economics: Micro and Macro Perspectives, University of California Santa Barbara, the CIREQ Montreal Macroeconomics Conference on Health and Old Age, the 2015 NBER Summer Institute, EFACR group, the FRB Kansas City, the FRB St. Louis Workshop on Macroeconomies and Low Skilled Labor Markets, the UIUC Mini Conference on Quantitative Macroeconomics, the 2015 Midwest Macro Meeting, and GRIPS. The views expressed in this paper are those of the authors, and they do not necessarily reflect the views of the Federal Reserve Bank of Philadelphia, the Federal Reserve Bank of Kansas City, or the Federal Reserve System.

${ }^{\dagger}$ Research Department, Federal Reserve Bank of Philadelphia, Ten Independence Mall, Philadelphia, PA 19106-1574. E-mail: makoto.nakajima@phil.frb.org.

${ }^{\ddagger}$ Research Department, Federal Reserve Bank of Kansas City, 1 Memorial Drive, Kansas City, MO 64198. E-mail: didem.tuzemen@kc.frb.org.
} 


\section{Introduction}

We analyze the interaction between the labor market and the health insurance market in response to the Patient Protection and Affordable Care Act, commonly called the Affordable Care Act (ACA), as well as the act's welfare implications, by constructing an equilibrium islands model with firm and worker heterogeneity. The ACA, which was signed into law in 2010 with the aim of achieving near-universal health insurance coverage, is one of the biggest reforms to the U.S. health-care system. The ACA is expected to affect not only health insurance decisions of firms and individuals but also labor market outcomes because a unique characteristic of the U.S. health insurance market is a tight link between employment and access to health insurance. Our rich model captures all the important features of the ACA and thus serves as a laboratory to analyze the possible implications of the reform. Using the model, we implement various counterfactual experiments to study the interaction between access to health insurance and the labor market.

The ACA's impact on the labor market has been debated. Under one component of the ACA (the employer mandate), firms with 50 or more full-time equivalent (FTE) employees are required to offer health insurance to full-time (FT) employees to avoid being penalized. In response, firms may might cut employment to stay below the 50-FTE-threshold or replace FT workers with part-time (PT) workers. Mulligan (2014) argues that the employer mandate acts as a tax on FT employment. He predicts an overall impact on average hours per employee that is essentially zero, but argues that the reform will reduce nationwide weekly employment rate by 3 percent. ${ }^{1}$ Differently, the Congressional Budget Office (2014) (CBO) emphasizes that the ACA will lead to a 1.5- to 2.0-percent decline in total hours because workers will voluntarily reduce hours worked as a result of the reform. Under the ACA, the existing strong link between (mostly FT) employment and health insurance provided by employers is weakened, and workers gain better access to fully or partially subsidized health insurance. As a result, workers do not need to cling to jobs that come with employer-provided health insurance (EHI). Different from these studies, we distinguish between supply-side and demand-side effects on changes in total hours worked and on shifts from FT to PT employment.

Our analysis extends the growing literature that studies the macroeconomic implications of health insurance reforms, such as Jeske and Kitao (2009), Hansen et al. (2014), and Pashchenko and Porapakkarm (2013), by adding health insurance (HI) decisions by firms as well as decisions on PT and FT employment by firms and workers. ${ }^{2}$ Recent work by

1 This paper discusses the results in Chapter 6 of Mulligan (2015).

2 Pashchenko and Porapakkarm (2013), Feng and Zhao (2014), Janicki (2011), and Jung and Tran (2016) analyze various aspects of the ACA using equilibrium models but abstract from firm-side decisions. 
Brügemann and Manovskii (2010) and Aizawa and Fang (2013) introduce HI decisions by heterogeneous firms, but without distinguishing between PT and FT employment. In particular, in our islands model, heterogeneous firms and heterogeneous individuals make decisions on labor demand and labor supply as well as providing and obtaining HI. Firms differ in productivity and benefits/costs of providing HI to workers. Firms hire both FT and PT workers and decide whether to offer HI to FT workers. Workers are subject to productivity and medical expense shocks, differ in age, decide whether to work FT or PT, and can obtain EHI (if offered), private health insurance (PHI), public health insurance (if eligible), or remain uninsured. We also extend the firm-side of the equilibrium model by introducing firms with different sizes as in Hopenhayn and Rogerson (1993). Firms have different sizes because of different productivities and decreasing-returns-to-scale technology. Within the context of the model, the ACA can be understood as a size-dependent distortionary policy, which Restuccia and Rogerson (2008) and Güner et al. (2008) study in different contexts. There are six main results from our model-based simulations. First, the ACA achieves the goal of near-universal health insurance coverage, by lowering the uninsured rate from 22.6 to 5.4 percent in the long-run. This is in line with the CBO's recent estimate. ${ }^{3}$ Recent data show that the uninsured rate declined by 5.5 percentage points since 2013 Q4 and was at 11.6 percent in 2015 Q3. ${ }^{4}$ Based on our estimates and the CBO's predictions, the uninsured rate will decline further. In our model, the decline is the largest among the young (ages 16 to 25), due to higher enrollment in expanded Medicaid. It is possible that our model overstates the long-run decline in the uninsured rate because in implementing the ACA we assume all states are expanding Medicaid, while in reality some states opted out of Medicaid expansion. Second, the ACA is found to improve social welfare, equivalent to a 0.5 percent increase in flow consumption. The gain comes from increased redistribution from higher-income to lower-income individuals as well as from healthier to less-healthy individuals, in line with the findings of Pashchenko and Porapakkarm (2013). However, the welfare gain might be underestimated because our model does not incorporate features such as better health insurance coverage improving health and better health inducing higher productivity. Although forcing all individuals to obtain health insurance alone can generate an even lower uninsured rate (2.1 percent), the individual mandate alone generates a small negative welfare effect because it lacks the redistribution achieved under the full ACA. In other words, achieving a low uninsured rate alone does not improve social welfare.

Third, in response to a popular claim that the ACA is turning the U.S. into a "part-time

3 The CBO predicts the uninsured rate will drop to 7 percent among the nonelderly population by 2018. See https://www.cbo.gov/sites/default/files/cbofiles/attachments/43900-2015-03-ACAtables.pdf.

4 See http://www.gallup.com/poll/186047/uninsured-rate-third-quarter.aspx. 
nation," we examine the effect of the ACA on the composition of PT and FT employment. Our model predicts 2.1 million more PT jobs and 1.6 million fewer FT jobs as a result of the ACA. We show that expansion of Medicaid and health insurance subsidies contribute the most, indicating that the increase in PT employment is mostly related to labor supply rather than labor demand, which is associated with the employer mandate.

Fourth, although the model predicts a sizable shift from FT to PT employment, the ACA's impact on total hours worked is a modest 0.36-percent decline. The size of the predicted decline is smaller than the CBO's existing estimate. However, by shutting down the general equilibrium channel, we find that labor supply declines by 3.3 percent, which is comparable to their estimates. Under the ACA, many workers leave FT jobs since they do not need one to obtain subsidized health insurance. Interestingly, the response of labor demand is found to be limited. Many large firms start offering health insurance to their FT employees but leave total labor demand little changed. Only a few reduce employment to avoid a penalty under the employer mandate. Besides, smaller firms respond to changes in wages, which mitigates the partial equilibrium effects.

Fifth, our model experiments suggest that leaving the "coverage gap" while not expanding Medicaid has sizable negative effects. Individuals fall into the coverage gap when their income is below the federal poverty level (FPL), but they do not qualify for Medicaid. When Medicaid is expanded under the ACA, these individuals qualify for Medicaid. However, many states opted out of Medicaid expansion, and individuals in the coverage gap cannot receive health insurance subsidies or Medicaid. Our experiments suggest that, if the coverage gap is left open nationally, 1.1 million more workers would end up uninsured. The welfare gain from the ACA drops to 0.06 percent with the coverage gap.

Lastly, in an additional experiment, we implement the 2006 Massachusetts Health-Care Reform, which is often cited as the blueprint of the ACA, in our model and find that the model's implications are consistent with what are observed during the post-reform period in Massachusetts. This can be taken as a validation of our model. Both in our model and in the data, the uninsured rate drops significantly after the reform, which is mostly related to increased enrollment in Medicaid. Although the proportion of workers with PHI increases slightly, the proportion of workers with EHI declines. Our general-equilibrium analysis complements existing studies about the Massachusetts Health-Care Reform, such as Hackmann et al. (2015), Kolstad and Kowalski (2016), and Becker and Tüzemen (2015). The rest of the paper is organized as follows. Section 2 discusses the elements of the U.S. health-care system pre- and post-ACA. Section 3 presents the model. Section 4 discusses the calibration. Sections 5, 6, and 7 report the main results. Lastly, Section 8 concludes. An on-line appendix presents further details and additional analyses. 
Table 1: Distribution of Health Insurance Choices Pre-ACA ${ }^{1}$

\begin{tabular}{lr}
\hline \hline Type of Health Insurance & Percent \\
\hline Employer-provided health insurance (EHI), policyholder & 49.3 \\
Employer-provided health insurance (EHI), dependent & 17.2 \\
Private health insurance (PHI), policyholder & 3.3 \\
Private health insurance (PHI), dependent & 0.9 \\
Medicaid & 4.6 \\
Other public health insurance & 2.0 \\
Uninsured & 22.7 \\
\hline \hline
\end{tabular}

${ }^{1}$ Source: Current Population Survey Annual Social and Economic Supplement. Averages of 2004 to 2006 among individuals in the labor force and between the ages of 16-64 are shown.

\section{U.S. Health Insurance Market Pre- and Post-ACA}

This section provides an overview of the U.S. health-care system before (Section 2.1) and after (Section 2.2) the implementation of the ACA.

\subsection{Pre-ACA U.S. Health-Care Market}

Table 1 shows the distribution of health insurance choices pre-ACA (averages of 2004 to 2006) among individuals in the labor force between the ages of 16 and 64 years. Two prominent characteristics of the pre-ACA U.S. health insurance market were (i) the majority of the nonelderly population was covered by health insurance provided by their employers, and (ii) the uninsured rate, at 22.7 percent, was quite high compared with other developed countries, many of which offer universal health care. The main goal of the ACA is to lower the uninsured rate significantly.

The prevalence of employer-based health insurance is confirmed by Table 1, which shows that 66.5 percent of the individuals in the labor force obtained employer-provided health insurance (EHI), either as a policy holder or as a dependent. Employers that offered health insurance shared the cost of the health insurance premiums with their employees. This type of insurance was provided by private insurers in the group insurance market. Health insurance costs were paid by both employers and employees using pre-tax income, which virtually subsidized employer-based health insurance.

Table 1 also shows that only 4.2 percent obtained nonemployer private health insurance (PHI), either as a policy holder or as a dependent. PHI was not subsidized like EHI, since the PHI premium was paid after-tax. Moreover, a major problem with this market was the exclusions based on pre-existing health conditions. Private insurers often denied coverage or 
offered only limited coverage with high premiums to those with pre-existing conditions. In the pre-reform period, 4.6 percent of the labor force obtained Medicaid, while 2.0 percent benefited from other publicly provided health insurance. ${ }^{5}$ Medicaid is a government insurance program for individuals of all ages whose income and resources are insufficient to pay for health care. It is the largest source of funding for health-related services for low-income individuals who are pregnant or with children, their children, and some individuals with disabilities. However, in nearly all states, childless adults were not eligible for Medicaid regardless of how low their incomes were.

\subsection{Overview of the ACA}

The ACA, signed into law in 2010 and implemented since 2014, aims to reduce the uninsured rate in the nation by expanding access to affordable health insurance for everyone. There are five key components described below. ${ }^{6}$

Individual Mandate: The individual mandate requires every citizen or legal resident to have health insurance that qualifies as minimum essential coverage starting on January 1 , 2014. If an individual chooses not to have health insurance coverage, the individual is required to pay a penalty that is either $\$ 695$ per person or 2.5 percent of the individual's annual income in 2016, whichever number is higher. ${ }^{7,8}$

Health Insurance Exchange: The ACA mandates creation of state-based marketplaces (exchanges) through which individuals can purchase health insurance. Each state is allowed to choose whether to manage its own exchange or defer to the federal management. Subsidies are provided through the exchanges. The ACA also mandates changes for the private insurance market, most notably removing the previous practice of denying coverage or charging higher rates for people with pre-existing conditions. However, certain factors such as age, tobacco use, family size, and geography can be used to determine insurance costs to the consumer, up to some predetermined ratios. Regarding age, health insurance premium rates cannot vary by more than 3:1 for individuals who are similar except for their age. As for tobacco use, the rates cannot vary more than 1.5:1 for similar individuals.

Health Insurance Subsidies: In order to assist individuals in purchasing health insurance, the ACA provides subsidies for individuals and families with incomes between 100 and

5 Mostly Medicare and military health care.

6 More detailed information can be found at http://www.healthcare.gov.

7 The size of punishment gradually rises until 2016. In 2014, the penalty was $\$ 95$ or 1 percent of income, whichever was greater. In 2015 , the penalty was $\$ 325$ or 2 percent of income, whichever was greater.

8 There is no penalty if the health insurance premium exceeds 8 percent of household income, the coverage lapse is less than or equal to 3 months, income is below the income tax filing threshold, or the person is Native American. However, we abstract from these details for simplicity. 
400 percent of the federal poverty level (FPL) when they purchase insurance at the health insurance exchanges. ${ }^{9}$ With the subsidies, the monthly premium paid is capped between 2 to 9.5 percent of total income, depending on income. Individuals with an option to obtain EHI are not eligible for health insurance subsidies.

Medicaid Expansion: Pre-ACA, Medicaid provided free or low-cost care for low-income individuals and families with children, pregnant women, and people with disabilities. The ACA expended Medicaid so that all individuals whose incomes are below 133 percent of the FPL are eligible for Medicaid. ${ }^{10}$ However, a Supreme Court ruling gave states an option to accept or decline the expansion. As a result, only 30 states and the District of Columbia have accepted the expansion. ${ }^{11}$ Whether a state decides to expand Medicaid is very important because of the so-called "coverage gap." 12 The coverage gap exists when individuals whose incomes are below 100 percent of the FPL (who are not eligible for the subsidies) are ineligible for Medicaid because their states declined Medicaid expansion. In pre-ACA, there were some states where Medicaid eligibility was as low as 50 percent of the FPL, and factors such as age, gender, and pregnancy affected eligibility. According to a report by the Kaiser Family Foundation, nearly four million poor, uninsured adults will fall into the coverage gap that results from states' decisions not to expand Medicaid. These individuals would have been newly eligible for Medicaid had their state allowed for Medicaid expansion. ${ }^{13}$

Employer Mandate: The employer mandate requires all large firms (those with 50 or more full-time equivalent (FTE) employees) to provide health insurance to their FT employees and dependents up to age 26 or pay a penalty. ${ }^{14}$ All employees working more than 30 hours per week are considered FT employees, while those working fewer than 30 hours per week are considered PT. ${ }^{15}$ To calculate the number of FTE employees, the hours of all PT employees

9 The FPL was $\$ 11,670$ for an individual and $\$ 23,850$ for a family of four in 2014 .

${ }^{10}$ The threshold is also often reported as 138 percent because of how income is defined under the ACA.

11 The states that have currently accepted Medicaid expansion are Alaska, Arizona, Arkansas, California, Colorado, Connecticut, Delaware, Hawaii, Illinois, Indiana, Iowa, Kentucky, Maryland, Massachusetts, Michigan, Minnesota, Montana, Nevada, New Hampshire, New Jersey, New Mexico, New York, North Dakota, Ohio, Oregon, Pennsylvania, Rhode Island, Vermont, Washington, and West Virginia. Utah is still debating.

12 See, for example, http://obamacarefacts.com/medicaid-gap/ for more details of the coverage gap.

${ }^{13} \mathrm{See} \quad$ http://kff.org/health-reform/issue-brief/the-coverage-gap-uninsured-poor-adults-in-states-that-donot-expand-medicaid-an-update/.

14 There are subsidies, in the form of a health-care tax credit, to small businesses (firms that hire less than 25 FTE employees) that pay low average wages. However, this is temporary (provided only for two years), and a majority of small firms do not benefit from the subsidies since they do not offer health insurance or they do not satisfy the wage requirement. Therefore, we abstract from the subsidies.

${ }^{15}$ Notice that employment size as measured by FTE does not change when a FT employee works more than 30 hours per week. However, longer hours by a PT worker may increase the firm's employment size if 
in a week are summed and divided by 30 hours, then added to the weekly number of FT workers. ${ }^{16}$ If a firm doesn't provide health insurance coverage to its FT employees the firm has to pay an annual penalty of penalty of $\$ 2,000$ per FT employee excluding the first 30 employees. ${ }^{17}$ Unlike employer contributions to employee premiums, the employer shared responsibility payment is not tax deductible.

\section{Model}

This section first describes the baseline model that represents the pre-ACA economy, then explains how a stylized version of the ACA is introduced to the baseline model. An on-line appendix provides a more detailed description of the model, as well as a discussion of the key simplifying assumptions.

\section{$3.1 \quad$ Firms}

There are measure one of atomless firms. For simplicity, we assume that firms are owned by capitalists, who receive profits of all firms as dividends each period and consume. A firm is characterized by $(a, z)$, where $z$ is the individual productivity. $a$ represents the idiosyncratic preference for offering health insurance (EHI) to employees. $a$ is multiplicative to firms' profits, capturing tax benefits from offering EHI. ${ }^{18}$ Its mean will be calibrated to be greater than one, which is consistent with the tax benefits of offering EHI. The type distribution of firms is denoted by $\chi_{a, z}$. Each period, a firm $(a, z)$ decides whether to offer insurance $(h=2)$ to its FT workers or not $(h=1)$ and how many FT workers $(n)$ and PT workers $(m)$ to hire. For simplicity, we assume that firms do not offer health insurance to PT workers.

Current profits for a firm $(a, z)$ that hires $(n, m)$ but does not offer health insurance to FT workers $(h=1)$ are as follows:

$$
f(a, z, n, m ; h=1)=z\left[\alpha\left(p_{1} n\right)^{\epsilon}+(1-\alpha)\left(\psi p_{3} m\right)^{\epsilon}\right]^{\frac{\theta}{\epsilon}}-w_{1} p_{1} n-\psi w_{3} p_{3} m,
$$

where $y=z\left[\alpha\left(p_{1} n\right)^{\epsilon}+(1-\alpha)\left(\psi p_{3} m\right)^{\epsilon}\right]^{\frac{\theta}{\epsilon}}$ is the production technology. The elasticity of substitution between FT and PT workers is constant, at $\frac{1}{1-\epsilon}$. $\alpha$ is the share parameter of the CES aggregation function. $\theta \in(0,1)$ represents the decreasing returns to scale of the production technology. $w_{1}$ is the wage per efficiency unit for a FT worker without EHI, while $w_{3}$ is the wage for a PT worker. $p_{1}$ and $p_{3}$ are the average productivities (efficiency

the worker's hours exceed 30. Therefore, there is a concern that employers may choose to have their FT employees work longer hours. This margin is abstracted from our analysis.

16 To be considered a FT or a PT employee, the employee must work more than 120 days in a year.

17 There is a different penalty formula for a firm which either doesn't offer minimum essential coverage, or provides coverage that is unaffordable.

18 Alternatively, we could assume that $a$ is additive to profits. We chose multiplicative $a$ because it is consistent with the fact that more of the larger firms offer health insurance to their employees. 
units) of the two types of workers. To avoid different firms having different compositions of workers, we assume that all firms hire from the same pool of workers every period, and thus the average productivities of workers of each type, $p_{1}$ and $p_{3}$, are the same across all firms. As a result, we do not keep track of different productivity of workers across different firms. $\psi \in(0,1)$ is a parameter that represents the working hours of a PT worker. The working hours of a FT worker are normalized to one.

Similarly, current profits for a firm that offers health insurance $(h=2)$ are as follows:

$$
f(a, z, n, m ; h=2)=a\left\{z\left[\alpha\left(p_{2} n\right)^{\epsilon}+(1-\alpha)\left(\psi p_{3} m\right)^{\epsilon}\right]^{\frac{\theta}{\epsilon}}-w_{2} p_{2} n-\psi w_{3} p_{3} m-q_{0}-\gamma q_{2} n k\right\} .
$$

Since a firm offering EHI to its FT workers hires these FT workers from a different pool, $p_{2}$ represents the average productivity of FT workers in the pool for firms that offer EHI, and $w_{2}$ is the wage for those workers. $q_{0}$ is the fixed cost of providing EHI to its FT workers, and $q_{2}$ is the insurance cost per worker. $\gamma$ is the proportion of the per-worker portion of the premium paid by the firm. $k$ is the fraction of FT workers who purchase EHI. Since we assume that the composition of workers is the same across all firms offering EHI, $k$ is same for all firms. a represents the idiosyncratic preference shock of a firm for providing EHI.

Since there is no dynamic aspect for the firm's decision problem, given prices, the decision of a firm of type $(a, z)$ can be characterized as follows:

$$
f(a, z)=\max \left\{\max _{n, m} f(a, z, n, m ; h=1), \max _{n, m} f(a, z, n, m ; h=2)\right\} .
$$

The optimal decision rules of firms can be denoted by $n=g_{n}(a, z), m=g_{m}(a, z)$, and $h=g_{h}(a, z) \cdot f(a, z)$ is the optimal profit.

\subsection{Workers}

There is measure $\bar{\mu}$ of workers. A worker is characterized by $(i, d, x, s, e)$, where $i$ is age, $d$ is preference for leisure, $x$ is medical expenditure in the previous period, $s$ is individual productivity, and $e$ denotes the island that the worker is currently in. $\mu_{i, d, x, s, e}$ represents workers' type distribution. Workers follow $i=1,2, \ldots, I$ stages of life and age stochastically, with probability $\pi_{i}$. Workers of age $I$ die with probability $\pi_{I}$ and are replaced by the same measure of newborns, which keeps the population size constant over time. The age of a worker affects the average productivity $\xi_{i}$ and the distribution of medical expenses. $d \in \mathbb{R}^{+}$ is drawn at birth and does not change over time, but $s \in \mathbb{R}^{+}$and $x \in \mathbb{R}^{+}$change over time following respective first-order Markov processes. ${ }^{19}$ Because of persistence, the medical expenditure $x$ in the previous period, together with age $i$, provides information about the

\footnotetext{
${ }^{19}$ We assume that shocks to $x$ and $s$ are not correlated, for simplicity.
} 


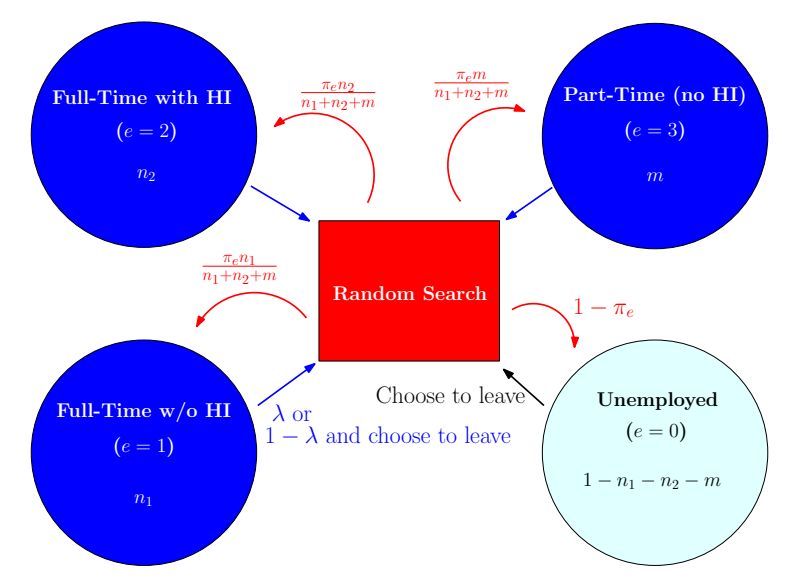

Figure 1: Labor Market Transitions in the Model

medical expenditure in the current period, which is realized after the decision about health insurance purchase is made.

A worker is in one of the four islands, denoted by $e \in\{0,1,2,3\} . e=0$ is the unemployment island, i.e., workers on island $e=0$ are currently unemployed. A worker on island $e=1$ is hired as FT by a firm that does not offer health insurance. A worker on island $e=2$ is hired as FT by a firm that offers health insurance. A worker on island $e=3$ is hired by a firm as PT. PT workers are not offered health insurance by assumption.

Figure 1 illustrates the labor market transitions in the model. A worker with a job is exogenously separated from her job with probability $\lambda$. When a worker leaves the current island, with probability $1-\pi_{e}$, the worker arrives in the unemployment island $(e=0)$. With probability $\pi_{e}$, the worker arrives in one of the islands with employment opportunities. In particular, with probability $\pi_{e} \frac{N_{1}}{N_{1}+N_{2}+M}$, the worker arrives in the island of FT jobs without insurance $(e=1)$, where $N_{1}, N_{2}$, and $M$ are the number of FT jobs without health insurance, the number of FT jobs with health insurance, and the number of PT jobs, respectively. With probability $\pi_{e} \frac{N_{2}}{N_{1}+N_{2}+M}$, the worker arrives in the island of FT jobs with health insurance $(e=2)$. With probability $\pi_{e} \frac{M}{N_{1}+N_{2}+M}$, the worker arrives in the island of PT jobs $(e=3)$. Intuitively, the relative probabilities of finding jobs depend on the relative number of jobs available. Taken together, the expected value of leaving an island and moving randomly to a different island can be characterized as follows:

$$
\widetilde{V}(i, d, x, s)=\left(1-\pi_{e}\right) \bar{V}(i, d, x, s, 0)+\pi_{e} \frac{N_{1} \bar{V}(i, d, x, s, 1)+N_{2} \bar{V}(i, d, x, s, 2)+M \bar{V}(i, d, x, s, 3)}{N_{1}+N_{2}+M},
$$

where $\bar{V}(i, d, x, s, e)$, the expected value with respect to aging, is characterized as follows:

$$
\bar{V}(i, d, x, s, e)=\pi_{i} V(i+1, d, x, s, e)+\left(1-\pi_{i}\right) V(i, d, x, s, e)
$$


with $V(I+1, d, x, s, e)=0$. With probability $(1-\lambda)$, the worker is not forced to leave the current island. In this case, the worker can stay in the current island or leave the island. If the worker chooses to leave, the worker arrives in a randomly assigned island.

The period utility of a worker is $u(d, c, \ell)=\log c-d \ell$, where $c$ is current consumption and $\ell$ denotes hours worked. Workers are risk averse, which makes health insurance valuable for workers, but we also assume, for simplicity, that workers cannot save. ${ }^{20}$ Workers discount future utility with a constant discount factor of $\beta$.

\subsection{Workers' Optimization Problems}

Now, let us formulate the workers' problems. We first describe the problem of FT workers with employer-provided health insurance (EHI, island $e=2$ ) and point out differences in the problems of workers on different islands. A worker who works FT for a firm that offers EHI can either accept EHI $(j=3)$, obtain private health insurance (PHI, $j=2)$, obtain Medicaid if eligible $(j=1)$, or remain uninsured $(j=0)$. The health insurance decision is made before the medical expenditure in the current period $x^{\prime}$ is drawn. Medicaid is available only when the current before-tax income is below a threshold $\bar{w}$. Consumption of a worker with $\left(i, x, x^{\prime}, s, e=2\right)$, conditional on the insurance purchase decision $j$, is as follows:

$$
\begin{aligned}
& c\left(i, x, x^{\prime}, s, e=2 ; j=0\right)=\left(1-\tau_{w}-\tau_{u}\right) \xi_{i} s w_{2}-x^{\prime} \\
& c\left(i, x, x^{\prime}, s, e=2 ; j=1\right)=\left(1-\tau_{w}-\tau_{u}\right) \xi_{i} s w_{2}-\left(1-\phi_{m}\right) x^{\prime} \\
& c\left(i, x, x^{\prime}, s, e=2 ; j=2\right)=\left(1-\tau_{w}-\tau_{u}\right) \xi_{i} s w_{2}-q_{1, i, x}-\left(1-\phi_{1}\right) x^{\prime} \\
& c\left(i, x, x^{\prime}, s, e=2 ; j=3\right)=\left(1-\tau_{w}-\tau_{u}\right) \xi_{i} s w_{2}-(1-\gamma) q_{2}-\left(1-\phi_{2}\right) x^{\prime},
\end{aligned}
$$

where $\tau_{w}$ is the individual income tax rate, $\tau_{u}$ is the payroll tax rate, $\xi_{i}$ is the age component of individual productivity, $s$ is the productivity shock, $w_{2}$ is the equilibrium wage for a FT job with EHI. The last term in the equations above vary depending on insurance choice. In case the worker is uninsured $(j=0)$, the worker pays the current medical expenses $x^{\prime}$ fully. If the worker obtains Medicaid $(j=1)$, the portion $\phi_{m}$ of the current medical expenses is covered by Medicaid, and the worker doesn't need to pay any insurance premium. If the worker obtains PHI, $\phi_{1}$ is the coverage ratio, and $q_{1, i, x}$ is the PHI premium. Remember that, pre-ACA, the PHI premium fully depends on the age $(i)$ and past medical expenses $(x)$ of the worker. Finally, in case the worker obtains EHI, $\phi_{2}$ of the current medical expenses are covered by the health insurance, and the worker pays for the fraction $1-\gamma$ of the per-worker insurance cost $q_{2}$. Notice that the worker pays for the community rating with EHI. A worker on this island is assumed to work for one unit of time, which means FT.

\footnotetext{
${ }^{20}$ Obviously, this assumption crucially affects the value of insurance. Exploring the implications of allowing workers to save is a topic for future research.
} 
The value for a worker with type $(i, d, x, s, e=2)$ is as follows:

$$
\begin{aligned}
V(i, d, x, s, 2) & = \begin{cases}\max _{j \in\{0,2,3\}} V_{j}(i, d, x, s, 2) & \xi_{i} s w_{2}>\bar{w} \\
\max _{j \in\{0,1,2,3\}} V_{j}(i, d, x, s, 2) & \text { otherwise }\end{cases} \\
V_{j}(i, d, x, s, 2) & =\sum_{x^{\prime}} \sum_{s^{\prime}} \pi_{i, x, x^{\prime}} \pi_{s, s^{\prime}}\left\{u\left(d, \max \left\{\underline{c}, c\left(i, x, x^{\prime}, s, 2 ; j\right)\right\}, 1\right)\right. \\
+ & \left.\beta\left(\lambda \widetilde{V}\left(i, d, x^{\prime}, s^{\prime}\right)+(1-\lambda) \max \left\{\bar{V}\left(i, d, x^{\prime}, s^{\prime}, 2\right), \widetilde{V}\left(i, d, x^{\prime}, s^{\prime}\right)\right\}\right)\right\} .
\end{aligned}
$$

where equation (10) represents the optimal health insurance decision. Notice that Medicaid $(j=1)$ is an available option only when the current income is below the income threshold $\bar{w}$. Equation (11) characterizes the value conditional on the health insurance decision. $\pi_{i, x, x^{\prime}}$ and $\pi_{s, s^{\prime}}$ are the Markov transition probabilities of $x$ and $s$, respectively. Notice that there is a consumption floor $\underline{c}$. Following Hubbard et al. (1995), we assume that the government offers a welfare program that basically guarantees a minimum consumption level $\underline{c}$. This welfare program captures, in a parsimonious manner, supplemental nutrition assistance program (SNAP), housing assistance, supplemental security income (SSI), temporary assistance for needy families (TANF), and so on. After the worker consumes, the worker is separated from the current job, with probability $\lambda$. In the other case, the worker can choose between keeping a FT job with EHI, or leaving the island and randomly arriving to a different island. The second max operator represents such a decision.

Let $g_{e}(i, d, x, s, e) \in\{0,1\}$ denote the decision of a worker to stay $\left(g_{e}=0\right)$ on the current island or leave $\left(g_{e}=1\right)$ the island. Also let $g_{j}(i, d, x, s, e) \in\{0,1,2,3\}$ denote the health insurance decision. $g_{j}(i, d, x, s, e)=3$ means obtaining EHI, $g_{j}(i, d, x, s, e)=2$ means purchasing PHI, $g_{j}(i, d, x, s, e)=1$ means obtaining Medicaid, and $g_{j}(i, d, x, s, e)=0$ means choosing to be uninsured. Note that we focus only on the labor force and do not have an out-of-labor-force state in the model. This is because (1) many insured individuals not in the labor force are dependent on their family members' health insurance plans, and we abstract from dependents in the model; and (2) we do not have any retirement or home production decisions that are a big component of flows in and out of the labor force.

There are two differences in the problem of a FT worker who is not offered EHI $(e=1)$. First, they do not have an option to obtain EHI $(j=3)$. Second, the wage rate is $w_{1}$, which is the market clearing wage of island $e=1$, instead of $w_{2}$. The rest is the same as the problem of a worker on island $e=2$.

The problem of a PT worker $(e=3)$ has three differences. First, EHI $(j=3)$ is not an option for them. Second, their pre-tax wage income is $\psi \xi_{i} s w_{3}$, where $w_{3}$ is the wage for a PT job. Third, they work $\psi$ hours instead of one (hours worked by a FT worker), which induces a lower disutility from work. 
Finally, the problem of an unemployed worker $(e=0)$ has four differences. First, EHI $(j=3)$ is not an option. Second, the after-tax income of an unemployed is $\left(1-\tau_{w}\right) \min \left\{\xi_{i} s w_{1} b, \bar{b}\right\}$, where $w_{1}$ is the wage for FT workers without EHI, $b$ is the replacement rate for unemployment insurance (UI) benefits, and $\bar{b}$ is the upperbound of UI benefits. Third, by definition, unemployed workers work zero hours $(\ell=0)$. Finally, unemployed workers do not face a separation shock $(\lambda)$ and choose whether to leave the unemployment island $(e=0)$ or not, with probability one.

\subsection{Health Insurance Market}

There are three types of health insurance: PHI, EHI, and Medicaid. There is no insurance premium for Medicaid. Medicaid is financed with the general government budget, which is described in the next section. PHI premiums depend on all the individual characteristics. We assume a perfectly competitive market, which implies zero profit from PHI for each type of worker. In other words, there is no cross-subsidization across different types in the equilibrium. The PHI premium $q_{1, i, x}$ for a worker of age $i$ and with the medical expenditure of $x$ in the previous period is characterized as follows:

$$
q_{1, i, x}=\sum_{x^{\prime}} \pi_{i, x, x^{\prime}} \phi_{1} x^{\prime}+\kappa_{1},
$$

where $\kappa_{1}$ is a fixed cost of PHI. The premium in the PHI market depends on a worker's characteristics $(i, x)$ because $x^{\prime}$ depends on age $i$ and medical expenditures from the previous period $x$.

On the contrary, EHI offers a community rating, i.e., EHI does not discriminate employees depending on individual characteristics. Since the composition of workers' types is the same across all firms regardless of the firm's size, the EHI premium can be characterized by the distribution of $(i, x)$ among workers on island $e=2$ and their take-up decisions. Moreover, we assume that a fraction $\kappa_{2}$ of the total costs is covered by the fixed cost $q_{0}$ that each firm has to pay. The remaining fraction $1-\kappa_{2}$ is paid by each employee obtaining EHI. The insurance premium per worker is $q_{2}$. Under these assumptions, the following equations characterize the zero-profit conditions for the EHI:

$$
\begin{aligned}
& q_{0}=\frac{\kappa_{2} \int \mathbb{1}_{g_{j}(i, d, x, s, 2)=3} \sum_{x^{\prime}} \pi_{i, x, x^{\prime}} \phi_{2} x^{\prime} d \mu_{i, d, x, s, 2}}{\int \mathbb{1}_{g_{h}(a, z)=2} d \chi_{a, z}} \\
& q_{2}=\frac{\left(1-\kappa_{2}\right) \int \mathbb{1}_{g_{j}(i, d, x, s, 2)=3} \sum_{x^{\prime}} \pi_{i, x, x^{\prime}} \phi_{2} x^{\prime} d \mu_{i, d, x, s, 2}}{\int \mathbb{1}_{g_{j}(i, d, x, s, 2)=3} d \mu_{i, d, x, s, 2}},
\end{aligned}
$$

where $\mathbb{1}$ is an indicator function that takes the value $1(0)$ if the condition attached is true (false). $g_{j}(i, d, x, s, 2)=3$ means that the worker of type $(i, d, x, s, 2)$ chooses to obtain EHI. Because of pooling, the premium is independent of $i$ or $x$ of a worker in the pool. 


\subsection{Government}

In the environment pre-ACA, the government administers three social insurance programs. First, the government provides unemployment insurance (UI) benefits. The amount of benefits is a fraction $b$ of labor income that the worker would have earned had the worker worked FT (without EHI), with a ceiling $\bar{b}$. Second, the government guarantees a consumption floor $\underline{c}$ for all workers. Third, the government provides Medicaid, which covers a fraction $\phi_{m}$ of medical expenses for those whose current before-tax income is below an income threshold of $\bar{w}$. The government finances UI benefits using a payroll tax of rate $\tau_{u}$. The remaining two programs are financed using a proportional income tax rate $\tau_{w}$. Assuming that the government balances its budget each period, its two budget constraints, which are satisfied with the tax rates $\tau_{u}$ and $\tau_{w}$, can be expressed as follows:

$$
\begin{aligned}
& \int\left[\mathbb{1}_{e=0} \min \left\{\xi_{i} s w_{1} b, \bar{b}\right\}\right] d \mu_{i, d, x, s, e}=\tau_{u} \int\left[\mathbb{1}_{e=1} \xi_{i} s w_{1}+\mathbb{1}_{e=2} \xi_{i} s w_{2}+\mathbb{1}_{e=3} \psi \xi_{i} s w_{3}\right] d \mu_{i, d, x, s, e} \\
& \int \sum_{x^{\prime}} \pi_{i, x, x^{\prime}}\left[\max \left\{\underline{c}-c\left(i, x, x^{\prime}, s, e ; g_{j}(i, d, x, s, e)\right), 0\right\}\right] d \mu_{i, d, x, s, e} \\
& +\int \sum_{x^{\prime}} \pi_{i, x, x^{\prime}}\left[\mathbb{1}_{g_{j}(i, d, x, s, e)=2} \phi_{m} x^{\prime}\right] d \mu_{i, d, x, s, e} \\
& =\tau_{w} \int\left[\mathbb{1}_{e=0} \min \left\{\xi_{i} s w_{1} b, \bar{b}\right\}+\mathbb{1}_{e=1} \xi_{i} s w_{1}+\mathbb{1}_{e=2} \xi_{i} s w_{2}+\mathbb{1}_{e=3} \psi \xi_{i} s w_{3}\right] d \mu_{i, d, x, s, e} .
\end{aligned}
$$

\subsection{Equilibrium}

Definition 1 (Steady-state equilibrium without the ACA) A steady-state equilibrium without the $A C A$ consists of $\chi_{a, z}, \mu_{i, d, x, s, e}, g_{h}(a, z), g_{n}(a, z), g_{m}(a, z), V(i, d, x, s, e), g_{e}\left(i, d, x^{\prime}, s^{\prime}, e\right)$, $g_{j}(i, d, x, s, e), q_{1, i, x}, q_{0}, q_{2}, w_{e}, p_{e} k, N_{1}, N_{2}, M, \tau_{u}$, and $\tau_{w}$ such that (i) $g_{h}(a, z), g_{n}(a, z)$, and $g_{m}(a, z)$ are the optimal decisions of the firm, (ii) $V(i, d, x, s, e)$ is the solution to the optimization problem of the worker, with $g_{e}\left(i, d, x^{\prime}, s^{\prime}, e\right)$ and $g_{j}(i, d, x, s, e)$ being the associated optimal decision rules, (iii) $\chi_{a, z}$ and $\mu_{i, d, x, s, e}$ are time invariant and consistent with the optimal decision rules, (iv) Insurance premiums $q_{1, i, x}, q_{0}$, and $q_{2}$ are characterized by equations (12), (13), and (14), respectively, ( $v) w_{1}, w_{2}$, and $w_{3}$ clear the labor market on the three islands. $N_{1}, N_{2}$, and $M$ are the market clearing supply of each type of labor, (vi) $p_{1}$, $p_{2}$, and $p_{3}$ are the average productivities of workers on the respective islands, (vii) $k$ is the proportion of workers who are offered EHI from their employers and take it, (viii) $\tau_{u}$ and $\tau_{w}$ satisfy the government's budget constraints (15) and (16), respectively.

\subsection{The Affordable Care Act}

We introduce a stylized version of the ACA into the baseline model described above. The ACA consists of five components: an individual mandate (IM), the establishment of the 
health insurance exchange (EX), individual health insurance premium subsidies (SU), Medicaid expansion (ME), and an employer mandate (EM). For simplicity, the additional expenses under the ACA are assumed to be financed through raising the proportional income tax rate $\tau_{w}$.

The IM, EX, SU, and ME directly affect the workers. Under the IM, workers have to either obtain health insurance or pay an annual penalty of $\$ 695$ or 2.5 percent of their income, whichever is greater. As for the EX, the PHI market in the model without the ACA is replaced by the exchange, where representative health insurance providers offer premiums that depend only on age. As a counterfactual exercise, we also study the case in which health insurance providers cannot offer age-dependent premiums. ${ }^{21}$ The PHI premium under the ACA satisfies the following zero-profit condition for each age group $i$, instead of (12).

$$
q_{1, i} \int \mathbb{1}_{g_{j}(i, d, x, s, e)=2} d \mu_{i, d, x, s, e}=\int \mathbb{1}_{g_{j}(i, d, x, s, e)=2} \sum_{x^{\prime}} \pi_{i, x, x^{\prime}} \phi_{1} x^{\prime} d \mu_{i, d, x, s, e} .
$$

When a worker purchases PHI from the exchange, the worker can receive subsidies (SU) if her income is between 100 and 400 percent of the FPL and if her employer does not offer EHI. The maximum premium that the worker has to pay is 2 percent of income if income is 100 to 133 percent of the FPL, 9.5 percent if income is 400 percent of the FPL, and linearly interpolated between 3 and 9.5 percent if income is 133 to 400 percent of the FPL. ${ }^{22}$ Moreover, all workers whose incomes are below 133 percent of the FPL can obtain Medicaid (ME) free of cost. ${ }^{23}$ We include Medicaid in the baseline model, where eligibility is only income-based for simplicity. Medicaid expansion of the ACA is modeled as raising the income threshold $\bar{w}$ for Medicaid eligibility.

As discussed earlier, an interesting feature is called the coverage gap, which happens in states that opt out of Medicaid expansion. The health insurance subsidies are available for individuals with incomes between 100 and 400 percent of the FPL. However, Medicaid without the expansion does not always cover individuals with incomes below 100 percent of the FPL. Some individuals cannot be eligible for either health insurance subsidies or Medicaid (without the expansion under the ACA) even though their incomes are below 100 percent of the FPL. These individuals fall in the coverage gap. We will come back to this issue when we study the experiment in which Medicaid expansion is not implemented.

On the firm side, under the EM, firms with 50 and more FTE employees have to offer health

${ }^{21}$ We abstract from the maximum ratio of $3: 1$ in HI premium according to age, but it turns out that variations of the equilibrium premiums for the three age groups only slightly exceed the 3:1 upperbound. 22 The actual formula is a step function between 3 and 9.5 percent.

23 The threshold is also often denoted as 138 percent because of how income is defined under the ACA. Our quantitative results are not significantly affected by the choice of 133 or 138 percent. 
insurance to their FT employees or pay a penalty. For a firm that hires $n$ FT workers and $m$ PT workers, its number of FTE workers is calculated as $n+\psi m$ because $\psi$ represents the fraction of time PT workers work relative to FT ones. The penalty is $\$ 2,000(n-30)$ and is applied to firms with more than 50 FTE employees. Notice that, although the EM does not require any firm to offer health insurance to PT employees, PT employment matters when a firm's size is calculated in terms of FTE employees.

\section{Calibration}

In this section, the baseline model without the ACA is calibrated to match the characteristics of the pre-ACA U.S. economy. In particular, whenever possible, we use the 2004-2006 averages of the U.S. data. Table 2 summarizes the calibration of parameters.

On the firms' side, we assume that a firm-specific productivity shock is distributed following a truncated (at $\underline{z}$ ) $\log$-normal distribution with standard deviation of $\sigma_{z} \cdot{ }^{24}$ A preference shock to offering health insurance is assumed to be uniformly distributed over $[\bar{a}-\widetilde{a}, \bar{a}+\widetilde{a}]$. These four and $\theta$, the curvature parameter representing decreasing returns, are calibrated to match related targets and will be discussed later. $\epsilon$ is calibrated to be 0.5 based on the elasticity of substitution between the FT and PT labor supply, which is 2.0. Mulligan (2014) also uses the elasticity of 2.0 in his analysis. Montgomery and Cosgrove (1993) estimate a range of 1.7 to 2.6 for the elasticity. In the on-line appendix, we implement a sensitivity analysis with a higher elasticity of substitution. Following Boedo and Mukoyama (2012), we set the curvature of the production function, $\theta$, to 0.64 .

On the workers' side, the aging and survival probabilities $\left(\pi_{i=1,2,3}\right)$ are set to satisfy (i) the average time spent as prime age (ages 26-54) is 29 years, (ii) the proportion of the young workers (ages 16-25) is 21.5 percent, and (iii) the proportion of old workers (ages 55-64) is 11.9 percent. These proportions are 2004-2006 averages from the CPS (ASEC). The medical expense shocks are constructed using MEPS Longitudinal Data for 2004-2005. The on-line appendix contains a detailed description on how the medical expense shocks are constructed. The age component of labor productivity $\left(\xi_{i=1,2,3}\right)$ is taken from median wage income in the MEPS. The annual discount factor, $\beta$, is set at 0.96 , a standard value. The proportion of time worked by PT workers, $\psi$, is set at 0.54 , which is the ratio of average hours among PT workers (23 hours) and those of FT workers (42.5). This is also consistent with Montgomery and Cosgrove (1993). We assume that the worker-specific productivity shock $s$ follows an $\operatorname{AR}(1)$ process with a persistence parameter of $\rho_{s}=0.90$ and a standard deviation of $\sigma_{s}=0.10$. These are the values in the middle of various estimates using micro data. The probability of

\footnotetext{
${ }^{24}$ Without truncation, the model generates far more smaller firms than in the data. The truncation can be interpreted as a fixed cost of operation that prevents firms with low productivity from operating.
} 
Table 2: Calibration: Baseline Model Without the $\mathrm{ACA}^{1}$

\begin{tabular}{|c|c|c|}
\hline Parameter & Description & Value \\
\hline \multicolumn{3}{|l|}{ Firm } \\
\hline$\epsilon$ & CES: Elasticity of substitution $=2.0$ & 0.5000 \\
\hline$\alpha$ & Share parameter of production function & 0.7610 \\
\hline $\bar{a}$ & Mean of distribution of $a$ & 1.2180 \\
\hline$\widetilde{a}$ & Range of distribution of $a$ & 0.2000 \\
\hline$\theta$ & Curvature of production function & 0.6400 \\
\hline$\sigma_{z}$ & Standard deviation of productivity shock & 1.0000 \\
\hline$\underline{z}$ & Threshold level of productivity shock & 1.1000 \\
\hline \multicolumn{3}{|l|}{ Worker } \\
\hline$\beta$ & Time discount factor & 0.9600 \\
\hline$\eta$ & Disutility of leisure & 1.4000 \\
\hline $\bar{d}$ & Step of preference shock & 0.2400 \\
\hline$\psi$ & Hours for a PT job & 0.5400 \\
\hline$\rho_{s}$ & Persistence of productivity shock & 0.9000 \\
\hline$\sigma_{s}$ & S.D. of productivity shock & 0.1000 \\
\hline$\lambda$ & Probability of leaving island & 0.2000 \\
\hline$\pi_{e}$ & Probability of employment & 0.8547 \\
\hline $\bar{\mu}$ & Total measure of workers & 23.0966 \\
\hline$\pi_{i=1}$ & Survival probability (young) & 0.8932 \\
\hline$\pi_{i=2}$ & Survival probability (prime-age) & 0.9655 \\
\hline$\pi_{i=3}$ & Survival probability (old) & 0.8067 \\
\hline$\xi_{i=1}$ & Average productivity (young) & 13,131 \\
\hline$\xi_{i=2}$ & Average productivity (prime-age) & 32,500 \\
\hline$\xi_{i=3}$ & Average productivity (old) & 33,500 \\
\hline \multicolumn{3}{|l|}{ Insurance } \\
\hline$\phi_{1}$ & Insurance coverage ratio $(\mathrm{PHI})$ & 0.7500 \\
\hline$\phi_{2}$ & Insurance coverage ratio $(\mathrm{EHI})$ & 0.7500 \\
\hline$\gamma$ & Proportion of EHI premium paid by employer & 0.8000 \\
\hline$\kappa_{1}$ & Extra cost of PHI & 0.0038 \\
\hline$\kappa_{2}$ & Proportion EHI premium covered by fixed cost per employer & 0.1800 \\
\hline \multicolumn{3}{|c|}{ Government } \\
\hline$b$ & UI replacement rate & 0.1440 \\
\hline $\bar{b}$ & Upperbound of UI benefits $(\times$ median income $)$ & 0.1920 \\
\hline$\underline{c}$ & Consumption floor & 0.0680 \\
\hline$\phi_{m}$ & Insurance coverage ratio (Medicaid) & 0.7500 \\
\hline $\bar{w}$ & Income threshold for receiving Medicaid $(\times$ FPL $)$ & 0.6300 \\
\hline
\end{tabular}


exogenously separating from a job, $\lambda$, is set at 0.20 , based on the average duration of a job (about 5 years). The total measure of workers, $\bar{\mu}$, is set at 23.1, which is consistent with the average employment size across all firms according to the Business Employment Dynamics (BED) statistics. The preference shock for leisure, $d$, is assumed to be uniformly distributed over $[1-\bar{d}, 1+\bar{d}]$. Remember that $\eta$ characterizes the mean of the disutility of leisure. The two parameters associated with disutility for leisure, $\eta$ and $\bar{d}$, together the probability of employment after leaving an island, $\pi_{e}$, will be calibrated to match closely related targets. The insurance coverage ratio for PHI, $\phi_{1}$, and EHI, $\phi_{2}$, are set at 0.75 . According to Jeske and Kitao (2009), for the middle quintile of individuals in terms of medical expenses, 59.4 percent of expenses are covered by health insurance. However, the coverage increases with medical expenses. According to the authors, the top 1 percent in terms of medical expenses enjoy a coverage ratio of 84.5 percent. $\phi_{1}=\phi_{2}$ is set at higher than 0.59 to take into account higher coverage at the top end of the medical expense distribution. The proportion of health insurance premiums of EHI paid by the employer $\gamma$ is set at 80 percent, following Jeske and Kitao (2009). The proportion of costs associated with EHI that are covered by fixed costs per participating firm, $\kappa_{2}$, is motivated by the evidence that smaller firms are less likely to offer health insurance because of the administrative costs of offering health insurance. Lee (2002) reports that total administrative costs make up 40 percent of incurred claims for firms with 1 to 4 employees, while the proportions are 18 percent for firms with 50 to 99 employees and 5.5 percent for firms with more than 10,000 employees. We calibrate $\kappa_{2}$ to be 0.18 because the focus of our exercises is firms with an employment size of about 50 . The additional cost of PHI, $\kappa_{1}$, is calibrated to match the PHI take-up rate.

The replacement rate for unemployment insurance (UI) benefits, $b$, is set at 0.144. Although the UI replacement ratio is typically 0.40 in the U.S. (Shimer (2005)), we take into account that the take-up rate of UI benefits is around 36 percent. This smaller $b$ can also be justified with the observation that the duration of UI benefits is 26 weeks in normal times. Since workers have a choice between a PT job and unemployment in the model, having $b$ close to 0.5 (i.e., close to $\psi$ ) makes it difficult to obtain a high fraction of workers working PT instead of being unemployed. The ceiling of UI benefits, $\bar{b}$, is set at 0.192 of the average wage income. The cross-state average of the maximum amount of UI benefits is about $\$ 420$ per week, which is about 0.53 of the median weekly wage income. We make the same adjustment for the replacement rate. The consumption floor is computed based on the evidence provided by Nakajima (2012). It is reported that the average weekly benefits under the food stamp program (Supplemental Nutrition Assistance Program) is $\$ 50$, which is about 0.068 of the median weekly wage income.

The insurance coverage ratio of Medicaid, $\phi_{m}$, is set at 0.75 , the same rate as for PHI. The 
Table 3: Calibration: Summary of Moments

\begin{tabular}{lrr}
\hline \hline Target $^{1}$ & Data & Model \\
\hline \% of unemployed workers & 5.64 & 5.64 \\
\% of FT workers & 79.17 & 79.25 \\
\% of PT workers & 15.19 & 15.11 \\
\% of uninsured workers & 22.65 & 22.64 \\
\% of workers receiving Medicaid & 6.69 & 6.61 \\
\% of workers purchasing private health insurance (PHI) & 14.49 & 14.45 \\
\% of FT workers with employer-provided health insurance (EHI) & 56.16 & 56.30 \\
\% of firms offering health insurance & 61.33 & 61.15 \\
\% of firms with fewer than 5 employees & 54.37 & 54.19 \\
\% of firms with more than 1,000 employees & 0.20 & 0.21 \\
FT wage / PT wage & 1.000 & 1.000 \\
\% of job-to-job transitions & 0.300 & 0.299 \\
\hline \hline
\end{tabular}

${ }^{1}$ All the worker-related proportions are shares of the total labor force.

income threshold for receiving Medicaid, $\bar{w}$, is calibrated to match the proportion of workers receiving Medicaid in an equilibrium before the ACA. ${ }^{25}$

Table 3 summarizes the calibration targets. Because we have 10 parameters that are endogenously calibrated, we choose 10 closely related targets to match. Table 3 contains 12 target statistics, but two - the proportion of FT workers and the uninsured rate - are obtained as residuals. We use the Current Population Survey (CPS) Annual Social and Economic Supplement (ASEC), average statistics for 2004 to 2006, to obtain targets associated with distribution of labor market status and health insurance choices. In order to make the data consistent with the model, we make several adjustments to the data, which is discussed in the on-line appendix. The probability of employment, $\pi_{e}$, is mainly associated with the unemployment rate. We manage to match exactly the unemployment rate in the data. The proportion of PT workers and the job-to-job transition rate are closely related to the disutility of labor, $\eta$, and the size of the shock to it, $\bar{d}$. We match these targets very closely. The extra cost of PHI, $\kappa_{1}$, is pinned down to match the proportion of workers purchasing PHI (14.5 percent). The income threshold for Medicaid, $\bar{w}$, is set at 63 percent of the FPL to

${ }^{25}$ In reality, prior to the ACA, Medicaid provided public insurance to low-income individuals, with a focus on parents, children, pregnant women, seniors, and individuals with disabilities. Since our model does not have those different categories of individuals, we assume that all workers whose income was below a certain (calibrated) threshold $\bar{w}$ were eligible for Medicaid pre-ACA. 
match the proportion of workers receiving Medicaid. Since the income threshold for Medicaid under the ACA is 133 percent of the FPL, the ACA implies relaxation of Medicaid eligibility. As a residual, the uninsured rate in the model (22.64 percent) matches closely its empirical counterpart (22.65 percent).

Two parameters, the mean, $\bar{a}$, and the range, $\widetilde{a}$, of the preference shock, are closely related to the firms' incentives to offer health insurance. The two associated targets are the proportion of firms offering health insurance to their FT employees (61.3 percent) and the proportion of FT workers who are offered EHI (56.2 percent). Both are obtained from the Employer Health Report of the Kaiser Family Foundation and Health Research and Education Trust, 20042006. Table 3 shows that we manage to match both targets. The two parameters associated with the firm size distribution - the standard deviation of productivity shock, $\sigma_{z}$, and the threshold level of productivity shock, $\underline{z}$ - are calibrated to match the proportion of firms with fewer than 5 employees (54.4 percent) and those with more than 1,000 employees (0.20 percent). In the calibrated model, 54.2 percent of the firms hire fewer than 5 employees, while 0.21 percent of the firms hire more than 1,000 employees. Finally, we assume that the hourly wages of FT (without EHI) workers and PT workers are the same in the baseline. ${ }^{26}$ This is achieved by pinning down the share parameter in the production function, $\alpha$.

\section{Results: Model vs. Data, Pre-ACA}

In this section, we compare various results from the model with the corresponding data from the U.S. economy before the ACA was implemented. Section 5.1 focuses on the workers' side and Section 5.2 discusses the firms' side.

\subsection{Workers' Side}

The first two panels of Table 4 compare the distribution across FT employed, PT employed, and unemployed individuals for the overall labor force as well as the three age groups. The first panel is based on the 2004 to 2006 averages from the CPS (ASEC), and the second panel is the model without the ACA. The third panel is associated with the model with the ACA, which will be discussed in Section 6. The first column shows the numbers from the entire labor force (ages 16-64). In the data, 79.2 percent of the labor force work FT, while 15.2 percent work PT. The remaining 5.6 percent are unemployed. The corresponding numbers in the baseline model are close because they are targeted in the calibration. What are not targeted are the differences across different age groups, which are shown in the remaining three columns. Although the only differences across different age groups are the

\footnotetext{
${ }^{26}$ In the data, the unconditional average wage income for FT employees is significantly higher than that for PT workers, but the comparison is affected significantly by (different) compositions of FT and PT workers. Therefore, we set the ratio of hourly wages to one.
} 
Table 4: Labor Market Outcomes: Model and Data ${ }^{1}$

\begin{tabular}{lrrrr}
\hline \hline & All & Young & Prime Age & Old \\
\hline Data (CPS 2004-2006) & & & & \\
Full-time (FT) employed & 79.17 & 54.53 & 86.55 & 82.44 \\
Part-time (PT) employed & 15.19 & 32.87 & 9.92 & 12.74 \\
Unemployed & 5.64 & 12.60 & 3.53 & 4.82 \\
\hline Baseline Model (Without the ACA) & & & \\
Full-time (FT) employed & 79.25 & 71.12 & 80.79 & 85.34 \\
Part-time (PT) employed & 15.11 & 20.00 & 14.41 & 10.18 \\
Unemployed & 5.64 & 8.88 & 4.80 & 4.48 \\
\hline Model with the ACA & & & & \\
Full-time (FT) employed & 78.22 & 74.01 & 78.99 & 81.57 \\
Part-time (PT) employed & 16.42 & 17.94 & 16.30 & 14.38 \\
Unemployed & 5.36 & 8.05 & 4.72 & 4.06 \\
\hline \hline
\end{tabular}

average labor productivities and the distribution of medical expenditures, both of which are calibrated using observable data (MEPS), the model captures the salient characteristics of the data. More specifically, (i) the proportion of FT employment is higher among prime-age and old workers, (ii) the proportion of PT employment is significantly higher among young workers, and (iii) the unemployment rate is significantly higher among young workers. In the model, young workers are more likely to work PT or are unemployed because they have a lower average income, which lowers their incentives to work FT, and because they face smaller medical expense risks, which weakens their incentives to search for FT jobs with EHI. On the other hand, the model does not replicate the following facts: (iv) the proportion of PT employment is higher among old workers than among prime-age workers, (v) the proportion of FT employment is lower among old workers than among prime-age workers, and that (vi) the unemployment rate is slightly higher among old workers than among prime-age workers. In the model, the proportion of PT employment and the unemployment rate monotonically decline with age. The discrepancy is most likely because the model does not feature a gradual transition from work to retirement among old workers.

The top two panels of Table 5 compare the health insurance choices between the data (top panel, from the CPS (ASEC)) and the baseline model (second panel). The bottom panel shows the model with the ACA, and thus we will come back to it in Section 6. Again, the first column shows the distribution of health insurance choices among all workers 16 to 64 
Table 5: Health Insurance Choices: Model and Data ${ }^{1}$

\begin{tabular}{lrrrr}
\hline \hline & All & Young & Prime Age & Old \\
\hline Data (CPS 2004-2006) & & & & \\
Employer-provided health insurance (EHI) & 56.16 & 27.06 & 63.81 & 65.95 \\
Private health insurance (PHI) & 14.49 & 26.71 & 10.38 & 15.44 \\
Medicaid & 6.69 & 10.47 & 5.58 & 6.09 \\
Uninsured & 22.65 & 35.76 & 20.23 & 12.51 \\
\hline Baseline Model (Without ACA) & & & & \\
Employer-provided health insurance (EHI) & 56.30 & 41.62 & 59.11 & 67.13 \\
Private health insurance (PHI) & 14.45 & 4.92 & 17.36 & 15.40 \\
Medicaid & 6.61 & 13.39 & 4.80 & 4.48 \\
Uninsured & 22.64 & 40.07 & 18.73 & 13.00 \\
\hline Model with the ACA & & & & \\
Employer-provided health insurance (EHI) & 54.80 & 12.44 & 65.95 & 69.00 \\
Private health insurance (PHI) & 14.58 & 3.40 & 17.62 & 17.72 \\
Medicaid & 25.18 & 77.68 & 11.10 & 9.05 \\
Uninsured & 5.44 & 6.47 & 5.32 & 4.23 \\
\hline \hline
\end{tabular}

${ }^{1}$ Percent of each age group.

years of age. In the data, 56.2 percent obtain employer-provided health insurance (EHI), 14.5 percent obtain health insurance from private health insurance providers (PHI), 6.7 percent obtain Medicaid, and 22.7 percent are uninsured. These numbers are closely matched by the model pre-ACA because they are targeted in the calibration. The remaining three columns show the distribution of the health insurance choices for the three age groups, which are not targeted in the calibration. The model replicates the features of the data that (i) the uninsured rate significantly declines with age, (ii) the proportion of workers obtaining EHI increases with age, and (iii) the take-up rate of Medicaid is higher among the young. In particular, the uninsured rate is 35.8 percent among the young and 12.5 percent among the old in the data, while it is 40.1 percent for the young and 13.0 percent for the old in the model. However, the model fails to replicate that (iv) the proportion of workers purchasing PHI is the lowest among prime-age workers and that (v) the Medicaid take-up rate is the lowest among the prime-age workers. As for (iv), the discrepancy is mainly due to the fact that there are no dependents in the model. In the data, many young workers obtain health insurance as a dependent of a policyholder of EHI, but we reclassify these individuals as obtaining PHI (see the on-line appendix). This reclassification helps us to keep the overall 


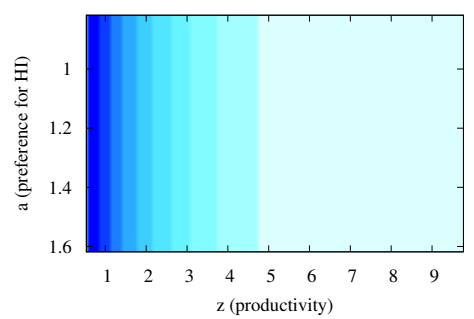

Figure 2: Firm Type Distribution

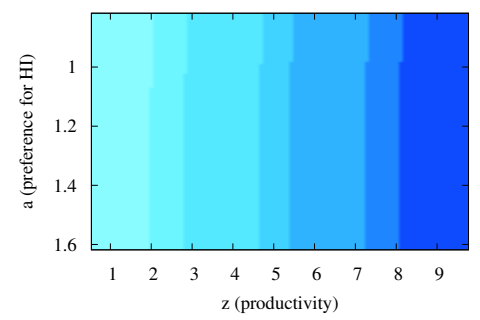

Figure 3: Firm Size Distribution

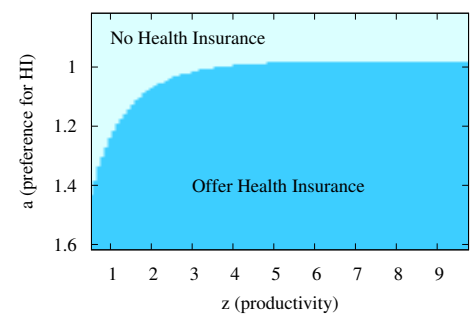

Figure 4: Firms' Health Insurance Decision

uninsured rate the same as in the data, but it inflates the number of workers obtaining PHI, especially among the young. As for (v), the discrepancy is due to the difference in Medicaid eligibility between the U.S. economy and the model economy. In the pre-ACA U.S., Medicaid eligibility depended on various factors other than income, which resulted in more old workers qualifying than they do in the model, in which the only criterion is low income. Overall, the model's performance is satisfactory in the sense that the model replicates (i) and (ii), which are the most important features in the data.

\subsection{Firms' Side}

Let us look at the nature of the firms' optimal decisions regarding employment and health insurance provision. Figure 2 summarizes the type distribution of firms. The x-axis represents productivity of individual firms, $z$, and the y-axis represents the preference shock for offering health insurance, $a$. The darker the color the higher the frequency. Because we assume a uniform distribution with respect to $a$, the firm type distribution is uniform in the direction of $a$. However, because we assume a truncated log-normal distribution for $z$, a large measure of firms is concentrated around very low productivity. Figure 3 summarizes the optimal employment decisions by firms of different types. We use the same $\mathrm{x}$ - and $\mathrm{y}$-axis as in the previous figure. Firm size is measured as the total employment in FTE employees. The darker the color the bigger the size. The darkest color represents firms with more than 500 FTE employees, and the lightest color represents fewer than 5 FTE employees. The two figures together imply that there are many small firms but only a few large firms. In particular, firms that hire 1 to 4 employees make up 54.4 percent of all firms, but they hire 5.2 percent of workers in the data. ${ }^{27}$ Firms that hire less than 50 employees make up 95.0 percent of all firms, but they hire only 29.9 percent of workers. On the other hand, firms that

$\overline{27}$ The data are from BED, 2004-2006. More detailed comparison between the data and the model is found in the on-line appendix. 
Table 6: Percent of Firms Offering EHI: Model and Data

\begin{tabular}{lrrrr}
\hline \hline Firm Size & $\begin{array}{r}\text { Data } \\
\text { (Not FTE) }\end{array}$ & $\begin{array}{r}\text { Baseline Model } \\
\text { (Not FTE) }\end{array}$ & $\begin{array}{r}\text { Baseline Model } \\
\text { (In FTE) }\end{array}$ & $\begin{array}{r}\text { Model with ACA } \\
\text { (In FTE) }\end{array}$ \\
\hline 9 or fewer & 49.0 & 54.8 & 55.2 & 55.2 \\
$10-24$ & 73.0 & 76.8 & 77.0 & 73.1 \\
$25-49$ & 87.0 & 78.9 & 79.2 & 68.8 \\
$50-199$ & 92.3 & 80.0 & 80.2 & 92.6 \\
200 or more & 98.3 & 80.7 & 80.8 & 91.8 \\
\hline 49 or fewer & 58.2 & 59.8 & 59.9 & 58.8 \\
50 or more & 94.0 & 80.2 & 80.3 & 92.4 \\
Overall & 61.3 & 61.1 & 61.1 & 60.7 \\
\hline \hline
\end{tabular}

hire more than 50 workers make up only 5.0 percent of all firms, but they hire 70.1 percent of all workers. Generally speaking, the model replicates the fact that a large majority of firms are small, but a very small fraction of large firms generate a large part of employment. In the model, firms with 1 to 4 employees make up 54.2 percent of all firms, and they hire 6.8 percent of the workers. Firms with less than 50 workers make up 93.3 percent of the firms, but they hire only 32.9 percent of the workers, while firms that hire more than 50 workers make up 6.7 percent of all firms but hire 67.1 percent. These features of the data are important in thinking about the effects of the ACA, particularly the employer mandate, because the table shows that only about 5 percent of firms are hiring more than 50 employees and thus are affected by the employer mandate. But at the same time, a small change in the employment decisions by these large firms may be important because they are responsible for two-thirds of the total employment.

Figure 4 summarizes the optimal health insurance provision decisions by firms. Not surprisingly, firms with a low $a$ are unlikely to offer health insurance, but firms with a high $a$ offer health insurance. Moreover, larger firms are more likely to offer health insurance than smaller firms. This property is obtained with the fixed cost component of health insurance premiums paid by firms offering health insurance. How do the health insurance decisions of firms in the model compare to the data? The first two columns of Table 6 compare the proportion of firms that offer EHI to employees between the U.S. data (first column) and the baseline model (second column). The last two columns compare the model pre- and post-ACA, which we will come back to in the next section. The U.S. data are the 2004 to 2006 averages of the proportions computed by the Kaiser Family Foundation and Health 
Research and Educational Trust (2004-2006). ${ }^{28}$ The overall proportion of firms offering EHI is 61.3 percent, which is one of the calibration targets and thus is closely replicated by the model. Moreover, the model replicates the fact that this proportion increases with firm size. If we consider small firms (firms that hire fewer than 50 employees) and large firms (firms with more than 50 employees) separately, 58.2 percent of small firms and 94.0 percent of large firms offer EHI in the data. In the model, the differences exist but are not as stark as in the data; in the model, 59.8 percent of small firms and 80.2 percent of large firms offer EHI. The fact that the model undershoots the EHI offer rate among large firms could imply that the effects of introducing the ACA might be overestimated. Large firms that do not offer health insurance are affected by the EM directly, and the model has more firms in this category than in the data.

\section{Results: The Affordable Care Act}

This section presents the main results of the paper - the effects of introducing the ACA into the baseline economy. Section 6.1 investigates the implications on the health insurance market. Section 6.2 focuses on the effects of the reform on the composition of FT and PT employment, and Section 6.3 discusses the reform's effect on total hours worked. Lastly, Section 6.4 studies the welfare implications of implementing the ACA.

\subsection{Effects on the Health Insurance Market}

The bottom two panels of Table 5 compare the choices regarding health insurance in the model pre-ACA (second panel) and post-ACA (bottom panel). Let us make four remarks. First, the uninsured rate drops from 22.6 percent pre-ACA to 5.4 percent post-ACA. Based on the model simulation, the ACA achieves its goal of near-universal health insurance coverage in the long run. According to the recent data, the uninsured rate has been declining since early 2014 when the individual mandate took effect. The uninsured rate among U.S. adults ages 18 years and older was 11.6 percent in 2015 Q3, reflecting a decline of 5.5 percentage points since 2013 Q4. ${ }^{29}$ Our model predicts that the uninsured rate will further decline as the transition continues toward the full implementation of the ACA. However, our model may overstate the long-run decline in the uninsured rate because we assume all states are expanding Medicaid, while in reality some states opted out. Second, the uninsured rate drops across all age groups, but the decline is the largest among the young. Their uninsured rate declines from 40.1 to 6.5 percent. This is mainly achieved by Medicaid expansion. The proportion of the young enrolling in Medicaid jumps up from 13.4 percent to 77.7 percent.

\footnotetext{
${ }^{28}$ In the data of Kaiser Family Foundation and Health Research and Educational Trust (2004-2006), the smallest size of firms is three employees.

${ }^{29}$ See http://www.gallup.com/poll/186047/uninsured-rate-third-quarter.aspx.
} 
Table 7: Effects of the ACA on the Health Insurance Market: Decomposition ${ }^{1}$

\begin{tabular}{|c|c|c|c|c|}
\hline & Employer HI & Private HI & Medicaid & Uninsured \\
\hline Baseline (without ACA) & 56.30 & 14.45 & 6.61 & 22.64 \\
\hline $\mathrm{ACA}$ & 54.80 & 14.58 & 25.18 & 5.44 \\
\hline \multicolumn{5}{|c|}{ Only One Component of the ACA Implemented } \\
\hline Only individual mandate & 58.95 & 32.36 & 6.63 & 2.06 \\
\hline Only HI exchange & 57.39 & 0.00 & 6.66 & 35.95 \\
\hline Only HI subsidies & 51.77 & 21.10 & 6.43 & 20.70 \\
\hline Only Medicaid expansion & 47.28 & 12.66 & 25.16 & 14.91 \\
\hline Only employer mandate & 61.57 & 11.31 & 6.80 & 20.32 \\
\hline \multicolumn{5}{|c|}{ One Component of the ACA Not Implemented } \\
\hline No individual mandate & 50.19 & 9.79 & 25.04 & 14.98 \\
\hline No HI exchange & 52.70 & 20.82 & 25.11 & 1.37 \\
\hline No HI subsidies & 60.15 & 0.56 & 24.77 & 14.52 \\
\hline No Medicaid expansion (with gap) & 65.48 & 21.74 & 6.45 & 6.33 \\
\hline No Medicaid expansion (without gap) & 63.41 & 24.29 & 6.65 & 5.65 \\
\hline No employer mandate & 49.42 & 18.01 & 25.08 & 7.50 \\
\hline No tax increase & 54.77 & 14.61 & 25.21 & 5.40 \\
\hline
\end{tabular}

${ }^{1}$ Percent of total labor force.

Because Medicaid is available to every individual whose income is below 133 percent of the FPL, a majority of young workers, whose income tends to be low, qualify for Medicaid even if they are working FT. Third, the proportion of workers covered by EHI declines, but slightly, from 56.3 to 54.8 percent. ${ }^{30}$ Even with the ACA, the health insurance market remains predominantly employer provided. The small decline is mainly due to the low-income young workers who receive Medicaid even if they are offered EHI from their employers. The proportion of workers with EHI increases among prime-age and old workers. Fourth, the take-up rate of private health insurance (PHI) through the exchange does not change much with the ACA. Fewer young workers obtain PHI under the ACA because more of them are eligible for Medicaid. On the other hand, the take-up rate of PHI increases among the prime-age and old workers. As will be shown, this is due to health insurance subsidies rather than the individual mandate.

Because the ACA is a collection of various components, an interesting question is how each

30 This result is in contrast to the findings in Gallen and Mulligan (2013). They calculate that 20 million people will leave ESI as a consequence of the ACA. 
component affects the health insurance market. Table 7 provides a decomposition. The first panel compares the percentage of workers (1) obtaining EHI, (2) purchasing PHI (from the exchange post-ACA), (3) obtaining Medicaid, and (4) remaining uninsured, pre- and postACA. In the second panel, only one of the five components of the ACA is introduced. Notice that, in case of health insurance subsidies, we assume the coverage gap is left open, i.e., workers with incomes between 63 and 100 percent of the FPL do not qualify for Medicaid nor receive subsidies. In the bottom panel, only one of the components of the ACA is not implemented. In case of no Medicaid expansion, two cases are shown: with and without the coverage gap left open. Moreover, we implement an experiment under which the tax rates are kept at the baseline levels to highlight the effects of higher taxes to finance the additional expenses of the ACA.

Let us make six remarks. First, raising tax rates to finance the ACA does not affect the health insurance choices much. Second, establishing the health insurance exchange and forcing pooling in the exchange itself raise the uninsured rate. If the pooling in the exchange is enforced without introducing all the other components of the ACA, almost nobody participates in the PHI market, and the uninsured rate becomes higher (36.0 percent) than in the baseline model. This is a typical adverse selection; enforced pooling in the PHI exchange drives away healthier workers who would subsidize less-healthy workers in the pooled market. Third, the individual mandate is crucial in lowering the uninsured rate. Just by introducing the individual mandate, the uninsured rate drops to 2.1 percent. If the individual mandate is removed from the ACA, the uninsured rate rises from 5.4 percent to 15.0 percent. The changes in the uninsured rate occur together with changes in the proportion of workers purchasing PHI. The individual mandate keeps healthier workers in the PHI market. An interesting question is, would welfare be higher if only the individual mandate is introduced and a lower uninsured rate is achieved? We will come back to this question in Section 6.4. Fourth, the employer mandate, as expected, forces more firms to offer EHI and thus increases the proportion of workers covered by EHI. However, the overall effect on the uninsured rate is modest. Without the employer mandate, the uninsured rate rises from 5.4 to 7.5 percent. Similarly, if the employer mandate alone is implemented, the uninsured rate drops from the baseline level of 22.6 to 20.3 percent. This is because the changes in the proportion of workers receiving EHI are accompanied by similar changes in workers obtaining PHI. Fifth, without health insurance subsidies, the exchange, in which health insurance providers are forced to pool the medical expense risks of all participants in the same age group, does not function. Very few (0.6 percent of the labor force) workers end up participating in it without the health insurance subsidies. Naturally, without the subsidies, the uninsured rate under the ACA is 14.5 percent instead of 5.4 percent. On the other hand, if health insurance subsidies alone 


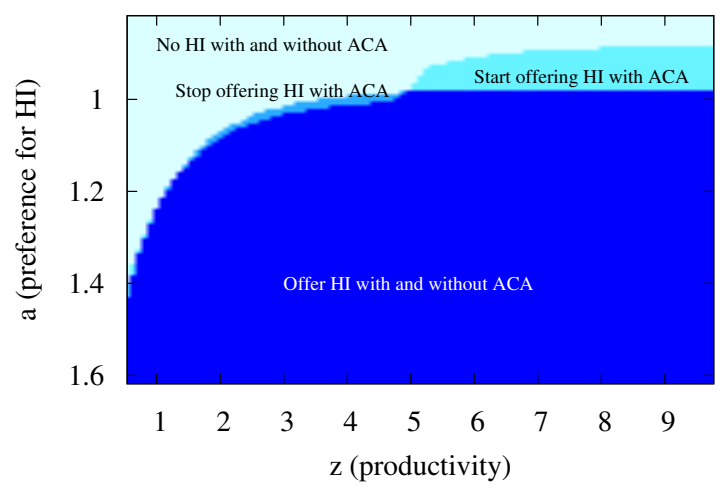

Figure 5: Effects of the ACA on Firms' Health Insurance Decisions

are introduced, the decline in the uninsured rate (22.6 percent to 20.7 percent) is limited. This generally just shifts workers from EHI to PHI without covering many workers who were uninsured without the subsidies.

Finally, not surprisingly, Medicaid expansion lowers the uninsured rate. If the ACA is implemented without Medicaid expansion, the uninsured rate is at 5.7 percent instead of 5.4 percent if the coverage gap is closed, but the uninsured rate goes up to 6.3 percent if there is a coverage gap. The former case occurs because workers who do not qualify for expanded Medicaid purchase subsidized PHI from the exchange. Remember that generous subsidies are available for those who do not qualify for expanded Medicaid. The uninsured rate is higher in the latter case because workers falling into the coverage gap cannot receive the subsidies. Therefore, they are discouraged from purchasing insurance from the exchange. This is an important point because many states declined to expand Medicaid, creating a coverage gap. According to our model, if Medicaid expansion is not nationally implemented while leaving the coverage gap open, about 1.1 million ( 0.7 percent of the labor force) more workers end up uninsured. Therefore, whether a state accepts or declines Medicaid expansion matters a lot in terms of the uninsured rate if there is a coverage gap. However, if the gap is closed and health insurance subsidies are made available to those who cannot benefit from expanded Medicaid because the state opted out, health insurance subsidies through the exchange are enough to keep the uninsured rate almost as low as in the case with Medicaid expansion.

Now let us look at the firms' side. Figure 5 summarizes the changes that the ACA causes in the firms' decisions regarding health insurance provision. The $\mathrm{x}$-axis and $\mathrm{y}$-axis represent productivity of individual firms $(z)$ and the preference shock for offering health insurance (a), respectively. Figure 5 shows that some large firms (high $z$ ) with relatively high $a$ start offering EHI under the ACA. This is the direct effect of the employer mandate. These firms hire more than 50 FTE employees and thus are subject to penalties if they do not 
offer health insurance. Because they have a relatively high preference for offering EHI, they start offering to avoid the penalty. However, two forces imply that the overall effects of the employer mandate is limited. First, the number of large firms that do not offer HI before the introduction of the ACA and thus are affected by the employer mandate is limited, as shown in Figure 2. Second, as we will discuss later, this direct effect causes wages for a FT job with EHI to go up and thus crowds out smaller firms. Figure 5 also shows that some smaller firms stop offering health insurance after the ACA goes into effect.

The third and the fourth columns of Table 6 compare the proportion of firms that offer EHI to employees in the model pre- and post-ACA. The numbers for the baseline model (third column) are different from the second column because we use FTE in the last two columns, while we use the unadjusted number of bodies in the first two columns. The overall proportion of firms offering EHI declines from 61.1 percent in the pre-ACA model (third column) to 60.7 percent with the ACA (fourth column). Among small firms (hiring fewer than 50 FTE employees) the proportion offering EHI declines from 59.9 to 58.8 percent. The decline is because of the lower offer rate among firms with 10 to 24 and 25 to 49 employees after the ACA. On the contrary, the proportion of large firms (hiring more than $50 \mathrm{FTE}$ employees) offering EHI rises from 80.3 to 92.4 percent as a direct effect of the employer mandate. Recall from Table 6 that the baseline model was underestimating the share of firms offering EHI among large firms. Therefore, it seems that the model overestimates the ACA's impact on the increase in the EHI offer rate for this category.

\subsection{Effects on the Labor Market: Part-Time Nation?}

Because large firms that hire more than 50 FTE employees do not need to offer health insurance to their PT workers, there are concerns, especially in the mass media, that the ACA will turn the U.S. economy into a "part-time nation." 31 We use our model to evaluate these concerns. The second and the bottom panels of Table 4 compare the model pre- and post-ACA. Using the most recent size of the labor force (157 million in June 2015), the ACA is expected to create 2.1 million more PT jobs (1.3 percentage point increase). At the same time, there will be 1.6 million fewer FT jobs (1.0 percentage point decline). Looking at different age groups, the increase in PT employment is concentrated among prime-age and old workers, and PT employment declines among young workers. This is because prime-age and old workers with high disutility of labor are the ones who switch to PT jobs under the ACA. Note that without the ACA, not many young workers qualify for Medicaid if they

${ }^{31}$ For example, see "Is Obamacare Forcing You to Work Part-Time?" Bloomberg View, August 13, 2013, and "Who Can Deny It? Obamacare Is Accelerating U.S. Towards Part-Time Nation," Forbes, July 31, 2013. For an argument against such concerns, see "The Spectacular Myth of Obama's Part-Time America - in 5 Graphs," The Atlantic, February 7, 2014. 
Table 8: Effects of the ACA on the Labor Market Outcomes: Decomposition ${ }^{1}$

\begin{tabular}{lrrr}
\hline \hline & FT Employed & PT Employed & Unemployed \\
\hline Baseline (without ACA) & 79.25 & 15.11 & 5.64 \\
ACA & 78.22 & 16.42 & 5.36 \\
\hline Only One Component of the ACA Implemented & & \\
Only individual mandate & 79.49 & 14.82 & 5.70 \\
Only HI exchange & 79.22 & 15.11 & 5.67 \\
Only HI subsidies & 78.66 & 15.80 & 5.53 \\
Only Medicaid expansion & 78.32 & 16.25 & 5.43 \\
Only employer mandate & 79.25 & 15.13 & 5.62 \\
\hline One Component of the ACA Not Implemented & & \\
No individual mandate & 78.24 & 16.38 & 5.38 \\
No HI exchange & 78.25 & 16.37 & 5.37 \\
No HI subsidies & 78.54 & 16.06 & 5.39 \\
No Medicaid expansion (with gap) & 78.71 & 15.74 & 5.54 \\
No Medicaid expansion (without gap) & 78.09 & 16.47 & 5.45 \\
No employer mandate & 78.30 & 16.37 & 5.32 \\
No tax increase & 78.27 & 16.42 & 5.31 \\
\hline \hline
\end{tabular}

${ }^{1}$ Percent of total labor force, in each model.

work FT, which makes PT jobs more attractive for some young workers. However, postACA, many young workers qualify for the expanded Medicaid even if they work FT. This causes a large shift among young workers to FT jobs.

Which component of the ACA generates such a shift from FT to PT employment? Table 8 shows a decomposition of the effects of the ACA on the composition of jobs. The first two rows show the proportion of FT and PT workers and the unemployed in the pre- and postACA model. In the second panel, only one of the components of the ACA is introduced. In the last panel, one of the components of the ACA is excluded. The second panel shows that Medicaid expansion and health insurance subsidies contribute to the increase in PT employment. Other components do not have any strong effects on the composition of jobs. This suggests that the effects of the ACA on hours worked are mostly through the labor supply channel; i.e., workers do not need to cling to FT jobs with EHI when the ACA is introduced, and workers can work PT and still obtain subsidized health insurance through either the exchange or Medicaid.

The third panel shows that removing one of the components from the ACA does not have a 
Table 9: Effects of the ACA on Hours, Output, Wages, and Productivity ${ }^{1}$

\begin{tabular}{|c|c|c|c|c|c|}
\hline & Baseline Model & \multicolumn{2}{|c|}{ Model with ACA } & \multicolumn{2}{|c|}{ PE (\% Change) } \\
\hline & Level & Level & $\%$ Change & Supply & Demand \\
\hline \multicolumn{6}{|c|}{ Total Hours Worked in FTE } \\
\hline Total & 20.19 & 20.12 & -0.36 & -3.31 & +0.73 \\
\hline FT total & 18.30 & 18.07 & -1.29 & -7.75 & +0.87 \\
\hline FT with EHI & 14.28 & 14.97 & +4.82 & -12.98 & +12.48 \\
\hline FT without EHI & 4.03 & 3.10 & -22.96 & +10.79 & -40.30 \\
\hline PT & 1.88 & 2.05 & +8.67 & +39.77 & -0.60 \\
\hline Output & 7.154 & 7.126 & -0.39 & - & +0.29 \\
\hline Wage for FT with EHI & 0.2207 & 0.2233 & +1.14 & - & . \\
\hline Wage for FT without EHI & 0.2327 & 0.2308 & -0.79 & - & - \\
\hline Wage for PT & 0.2326 & 0.2200 & -5.39 & - & - \\
\hline
\end{tabular}

${ }^{1} \mathrm{FTE}=$ Full-time equivalent. One PT worker is counted as 0.54 FTE. PE = Partial equilibrium, where wages and tax rates are held at the levels in the baseline model without the ACA.

strong effect on the composition of jobs, except for one case, in which Medicaid expansion is removed when the coverage gap is present. Removing either Medicaid expansion (without the coverage gap) or health insurance subsidies does not have a significant effect because the two components are substitutes. For example, when only Medicaid expansion is removed, many workers who could have received Medicaid under the expansion can still obtain subsidized health insurance at the exchange. This substitution mitigates the effects of removing either Medicaid expansion or health insurance subsidies. However, when the coverage gap is left open, removing Medicaid expansion brings the share of PT employment closer to the baseline share because health insurance subsidies cannot substitute for Medicaid expansion.

\subsection{Effects on the Labor Market: Aggregate Hours Worked}

Although the ACA is intended to achieve near-universal health-care coverage in the nation, there are concerns about possible negative incentive effects in the labor market. Mulligan (2014) estimates that the ACA will reduce weekly employment rate by 3 percent with no effect on average hours per employee. Congressional Budget Office (2014) estimates a total reduction in hours between 1.5 and 2.0 percent. Although both estimates of the effect of the ACA on the labor market are large, the main channels behind these numbers are very different. On the one hand, Mulligan (2014) focuses on the labor demand channel. He emphasizes that various components of the ACA are virtually additional taxes on employment, 
especially on FT employment. On the other hand, the Congressional Budget Office (2014) emphasizes the labor supply effect. It states that "the reason for the reduction in the supply of labor is that the provisions of the ACA reduce the incentive to work for certain subsets of the population." 32 Using our equilibrium model, we can evaluate both effects in a unified manner.

Table 9 shows how the ACA affects output, hours worked, and wages in the model. The first column shows the levels in the baseline model pre-ACA. The second and third columns show the levels and percent changes when the ACA is introduced. Changes in employment are shown in FTE. Overall, total employment in FTE declines, but modestly, by 0.36 percent. FT employment declines by 1.29 percent, but PT employment increases by 8.67 percent. Among FT employment, jobs shift from those without EHI to those with EHI, as more firms start offering EHI under the employer mandate. The former decreases by 22.96 percent, while the latter increases by 4.82 percent. The resulting change in total output is a moderate 0.39 percent decline. The third panel of Table 9 shows the changes in wages post-ACA. The wage for a FT job with health insurance increases by 1.1 percent, because more firms, especially larger firms, start offering EHI under the ACA. On the contrary, the wage for a FT job without EHI declines by 0.8 percent. More workers are happy with a job without EHI, since they can obtain health insurance either from the exchange or Medicaid. At the same time, fewer firms offer jobs without EHI, reducing the demand for workers to fill these jobs. Turning to PT jobs, the wage rate declines by 5.4 percent, although firms hire more PT workers to avoid being penalized by the employer mandate. Note that after the ACA, workers with relatively high disutility of labor will prefer to work PT rather than FT, since the reform allows them to receive subsidies when they obtain health insurance either from the exchange or Medicaid. The increase in labor supply outweighs the increase in labor demand, which pushes down the PT wage in the equilibrium.

Figure 6 summarizes how firms' decisions regarding employment size are affected by the ACA. The $\mathrm{x}$-axis and $\mathrm{y}$-axis represent individual productivity $(z)$ and the preference shock for offering EHI $(a)$, respectively. In particular, the figure shows the firms that hire fewer than 50 FTE with and without the ACA, the firms that hire more than 50 FTE with and without the ACA, and the firms that hire more than 50 FTE without the ACA but cut down employment to stay below 50 FTE under the ACA. The number of firms that move in the opposite direction turns out to be negligible, and thus they are not shown. It is easy to see that firms that are close to 50 FTE and have a relatively weak preference for offering health insurance lower employment to stay below the 50 FTE threshold. However, the number of

${ }^{32}$ In a lengthy qualifying statement, the $\mathrm{CBO}$ warns readers not to interpret its results to mean that 2.0 to 2.5 million workers lose their jobs because of the ACA. See https://www.cbo.gov/publication/45096. 


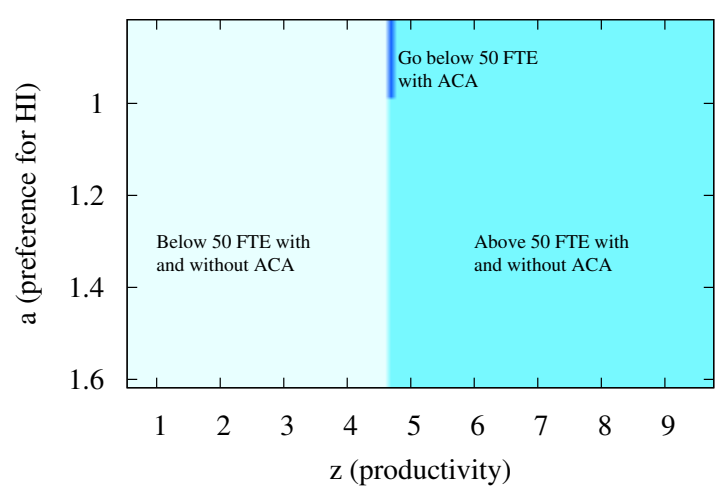

Figure 6: Effects of the ACA on Firms' Employment Sizes

Table 10: Effects of the ACA on Hours Worked: Decomposition ${ }^{1}$

\begin{tabular}{lrrr}
\hline \hline & Total Hours & PT Hours & $\% \geq 50$ FTE \\
\hline Baseline (without ACA) & 20.19 & 1.88 & 6.19 \\
ACA & 20.12 & 2.05 & 5.69 \\
\hline Only One Component of the ACA & Implemented & \\
Only individual mandate & 20.21 & 1.85 & 6.19 \\
Only HI exchange & 20.18 & 1.88 & 6.18 \\
Only HI subsidies & 20.14 & 1.97 & 6.17 \\
Only Medicaid expansion & 20.12 & 2.03 & 6.17 \\
Only employer mandate & 20.19 & 1.89 & 5.78 \\
\hline \hline
\end{tabular}

${ }^{1}$ Hours are shown in FTE. One PT worker is counted as 0.54 FTE.

firms that shed employment is small, especially because there are only a few firms that are productive enough to hire 50 FTE from the beginning (Figure 2).

Table 10 decomposes the effects of each component of the ACA on total hours worked. The first and second columns show the total (including both FT and PT) hours and total PT hours under different models. The third column shows the proportion of firms that hire more than 50 FTE employees. This is the proportion of firms that are subject to the employer mandate under the ACA. When only one of the components of the ACA is implemented, Medicaid expansion and health insurance subsidies have sizable negative effects on total hours worked. This confirms that the reduction in total hours is due to the labor supply channel workers reduce hours when the ACA is introduced. Interestingly, total hours worked declines even without a significant change in the proportion of large firms. Although the employer mandate induces the proportion of firms that hire more than 50 FTE to decrease from 6.2 percent to 5.7 percent, the overall effect of the employer mandate on total hours worked is 
limited.

Our model indicates that the effects of the ACA on aggregate hours worked is smaller than other estimates. Why? To better understand what is behind, we implement an additional experiment in which all the components of the ACA are introduced, but the prices in the labor markets are fixed at the pre-ACA levels. In particular, we fix $w_{e}$ and $p_{e}, \forall e$, to single out the effects of changing wages and productivities. The last two columns of Table 9 show the responses of labor supply (workers) and labor demand (firms), respectively. Notice that we do not allow wages to adjust to clear the labor markets. The ACA induces a significant decline in labor supply ( -3.3 percent), because workers are less desperate to obtain subsidized health insurance associated with FT employment. Surprisingly, labor demand increases slightly (+0.73 percent). Although the ACA induces a large shift from FT jobs without EHI to those with EHI, the total impact on labor demand is small. When large firms are forced to offer health insurance, they tend to increase employment, because they face relatively lower average costs of offering EHI. Some firms cut down FT employment to stay below the 50FTE threshold under the ACA, but the number of such firms is limited. All in all, without the general equilibrium effect, the decline in labor supply ( -3.3 percent) is comparable to other existing estimates (between -1.5 and -3 ). But, the total effect becomes small and negative when the general equilibrium effect is taken into consideration.

\subsection{Welfare Implications of the ACA}

We investigate the welfare implications of the ACA. As for the welfare criteria, we use exante expected lifetime utility of a newborn in the steady state, and convert the welfare in an alternative model by computing the consumption equivalence variation (CEV) to make welfare in the baseline model equal to the welfare in the alternative model. If the CEV is positive (negative), a newborn is better off (worse off) by being born into the steady state of the post-ACA model. ${ }^{33}$ In Table 11, the first column shows the welfare effects of the ACA and its components. The remaining columns show the uninsured rate, total hours worked, and the two tax rates $\left(\tau_{w}\right.$ and $\left.\tau_{u}\right)$, all of which are important for welfare.

Let us make seven remarks about the welfare numbers. First, the ACA implies a welfare gain equivalent to 0.52 percent of flow consumption. Because we do not incorporate features such as health insurance coverage improving health and health improving productivity, this is a conservative estimate. The welfare gain is due to redistribution to lower-income workers through Medicaid and health insurance subsidies and the fact that the ACA relaxes the link between FT employment and access to health insurance. We verify our conjecture with a

33 This is a common criterion used in macroeconomics with heterogeneity. For example, see Conesa et al. (2009). The precise definition of the welfare criteria is found in the on-line appendix. 
Table 11: Welfare Effects of the $\mathrm{ACA}^{1}$

\begin{tabular}{lcrrrr}
\hline \hline & Welfare & \% Uninsured & Hours & $\tau_{w}(\%)$ & $\tau_{u}(\%)$ \\
\hline Baseline (without the ACA) & - & 22.64 & 20.19 & 0.80 & 0.83 \\
ACA & +0.52 & 5.44 & 20.12 & 1.64 & 0.80 \\
ACA (age-independent premium) & +0.52 & 5.56 & 20.12 & 1.63 & 0.80 \\
\hline Only One Component of the ACA & Implemented & & & & \\
Only individual mandate & -0.08 & 2.06 & 20.21 & 0.65 & 0.83 \\
Only HI exchange & -0.18 & 35.94 & 20.18 & 0.92 & 0.83 \\
Only HI subsidies & +0.15 & 20.70 & 20.14 & 1.71 & 0.81 \\
Only Medicaid expansion & +0.58 & 14.91 & 20.12 & 1.63 & 0.81 \\
Only employer mandate & +0.02 & 20.32 & 20.19 & 0.54 & 0.83 \\
\hline One Component of the ACA Not Implemented & & & & \\
No individual mandate & +0.45 & 14.98 & 20.11 & 1.81 & 0.80 \\
No HI exchange & +0.47 & 1.37 & 20.12 & 1.74 & 0.80 \\
No HI subsidies & +0.57 & 14.52 & 20.14 & 1.06 & 0.80 \\
No Medicaid expansion (with gap) & +0.06 & 6.33 & 20.14 & 1.02 & 0.82 \\
No Medicaid expansion (without gap) & +0.28 & 5.65 & 20.09 & 1.13 & 0.80 \\
No employer mandate & +0.64 & 7.50 & 20.13 & 1.97 & 0.79 \\
No tax increase & +1.13 & 5.40 & 20.13 & 0.80 & 0.83 \\
\hline \hline
\end{tabular}

${ }^{1}$ Welfare is defined as the ex-ante expected lifetime utility of a newborn, and expressed as consumption equivalent variation $(\mathrm{CEV})$, relative to the baseline model. Hours are total hours worked in FTE.

series of experiments in the second and third panels of Table 11. Second, the third line of the first panel shows the results from an alternative model economy in which the premium at the exchange is not allowed to vary with age. The rest of the ACA is implemented as before. The experiment shows that prohibiting the age-dependent premium at the exchange does not have a sizable welfare effect. Why? Although prime-age and old workers benefit from pooling across age groups, young workers lose. The welfare loss while young affects the lifetime utility more than the welfare gains in the prime-age and old stages of life. Third, according to the second panel, in which only one component of the ACA is implemented in each experiment, most of the welfare gains of the ACA are coming from Medicaid expansion and health insurance subsidies. This result is consistent with our conjecture that welfare gains are due to redistribution, and align with the findings of Pashchenko and Porapakkarm (2013). ${ }^{34}$ Fourth, a lower uninsured rate does not necessarily mean a positive welfare effect.

\footnotetext{
34 They take into account the transition from the initial steady-state pre-ACA to the one post-ACA. They
} 
Interestingly, if only the individual mandate is implemented, the uninsured rate drops to 2.1 percent, and the welfare effect is negative $(-0.1$ percent). Forcing workers to obtain health insurance without subsidies does not improve welfare per se. Fifth, according to the last panel, in which one of the components of the ACA is excluded, the ACA generates a higher welfare gain if the employer mandate is not implemented. This is because the employer mandate has distortionary effects on firms' decisions on hiring as in Restuccia and Rogerson (2008) and Güner et al. (2008). Meanwhile, removing the individual mandate, which is another controversial component of the ACA, implies a lower welfare gain from the ACA. As shown in Table 7, without the individual mandate, many relatively healthy workers stay away from the health insurance exchange, which weakens the role of the exchange in subsidizing lower-income less-healthy workers. Sixth, obviously, if taxes do not need to be raised to finance the extra fiscal burden of the ACA, the welfare effect of the ACA is larger, at 1.1 percent of flow consumption. Finally, leaving the coverage gap while declining to implement Medicaid expansion has serious welfare consequences. This result is important because many states are choosing this option. When Medicaid expansion is removed but the coverage gap is closed, the welfare gain is 0.28 percent, which is lower than the full ACA (0.52 percent) but still sizably positive. However, if the coverage gap is left open with no Medicaid expansion, the welfare gain from implementing the ACA decreases significantly, to 0.06 percent. Although we assume Medicaid expansion is removed nationally, and thus the result cannot be easily interpreted, this experiment suggests a significant welfare cost of opting out, especially while leaving the coverage gap open.

\section{Results: Massachusetts Health-Care Reform}

This section provides an analysis of the Massachusetts Health-Care Reform (MA Reform), which was implemented starting in 2007. ${ }^{35}$ Since the two reforms share a lot of similarities, the MA Reform is often cited as the blueprint for the ACA. As with the ACA, the MA Reform had five main components. We leave the details of each component to the on-line appendix, but let us mention two key differences. First, health insurance subsidies were more generous and the income threshold for Medicaid eligibility was lower in the MA Reform. Second, penalties under the individual mandate and the employer mandate were less severe under the MA Reform. The latter was $\$ 295$ per FT employee. The second and the third columns of Table 12 compare the effects of the ACA and the MA Reform, using our calibrated model. As with the ACA experiment, we assume that $\tau_{w}$ is adjusted to finance additional expenses

\footnotetext{
calculate a welfare gain of 0.64 percent in CEV. However, they do not model decisions on the firms' side.

35 The on-line appendix contains details of the MA Reform and the model experiments associated with the MA Reform.
} 
Table 12: The ACA and Massachusetts Health-Care Reform ${ }^{1}$

\begin{tabular}{lrrr}
\hline \hline & No ACA & The ACA & MA Reform \\
\hline EHI & 56.30 & 54.80 & 47.96 \\
PHI & 14.45 & 14.58 & 18.55 \\
Medicaid & 6.61 & 25.18 & 29.54 \\
Uninsured & 22.64 & 5.44 & 3.95 \\
\hline FT employed & 79.25 & 78.22 & 78.29 \\
PT employed & 15.11 & 16.42 & 16.34 \\
Unemployed & 5.64 & 5.36 & 5.37 \\
\hline Total hours worked & 20.19 & 20.12 & 20.12 \\
Welfare in CEV (\%) & - & +0.54 & +0.60 \\
\hline \hline
\end{tabular}

${ }^{1}$ Percentage of the total labor force. $\mathrm{CEV}=$ Consumption equivalent variation.

under the MA Reform. A comparison between the two columns reveals that the MA Reform achieves a lower uninsured rate (4.0 percent) than the ACA (5.4), and the welfare gain is larger $(+0.60$ percent) than with the ACA $(+0.54)$. Because health insurance subsidies are more generous and Medicaid is available for workers with even higher incomes, the proportion of workers obtaining Medicaid and subsidized PHI is higher under the MA Reform. On the other hand, because the employer mandate penalty is lower, fewer firms offer EHI and fewer workers obtain EHI in MA. Although the more generous nature of the MA Reform requires a higher tax to finance the reform (2.2 percent in the MA Reform versus 1.6 percent under the ACA), a more extensive redistribution leads to a higher welfare gain under the MA Reform. In terms of the labor market outcomes, the composition among FT employment, PT employment, and unemployment is similar under the two reforms. In both cases, workers are less attached to FT employment with health insurance. As a result, PT employment increases to around 16.4 percent under both reforms.

How well does our model capture changes in Massachusetts in the post-reform period? One advantage of analyzing the MA Reform is that more post-reform data are available. We compare labor market outcomes and health insurance enrollment in Massachusetts pre-reform (2002-2005) and post-reform (2007-2012) using CPS (ASEC) and find that (i) the uninsured rate drops significantly after the implementation of the reform, (ii) this is mostly due to increased enrollment in Medicaid, (iii) the proportion of workers with PHI increases slightly, (iv) the proportion of workers with EHI declines slightly, and (v) PT employment, especially among the young, increased. ${ }^{36}$ All of these features in the data are consistent with the ${ }^{36} \mathrm{~A}$ more detailed analysis of the Massachusetts data is presented in the on-line appendix. 
model's predictions, which is a validation of the prediction power of our model, although some of the changes in Massachusetts (e.g., the observed shift of FT to PT employment) might be a result of the Great Recession too.

\section{Conclusion}

The ACA is considered the most fundamental reform in the U.S. health insurance market since the introduction of Medicare and Medicaid in 1965. The ACA may affect the labor market significantly, because of the link between access to health insurance and employment in the U.S. Indeed, there are concerns that hours worked may be negatively affected by the ACA, partly due to FT jobs being replaced by PT jobs. Against such background, we have studied the long-run implications of the ACA in a general equilibrium model that is rich enough to capture all the key features of the ACA. Our experiments indicate that the ACA achieves its goal of near-universal coverage and generates a welfare gain of 0.5 percent. The uninsured rate in the U.S. has already started declining, which validates our model. Our model also predicts that 2.1 million more part-time jobs are created at the expense of 1.6 million full-time jobs because of the weakened link between full-time employment and access to health insurance. The ACA induces a decline in total hours worked, but the size of the decline (0.36 percent) is smaller than other existing estimates (1.5 to 3.0 percent). Labor supply declines in response to the ACA, but the general equilibrium effect mitigates the response of the supply side.

Let us conclude by mentioning three promising areas of future research. First, the model developed in our paper can be used to investigate the optimal design of the health insurance system. Second, many individuals obtain health insurance as dependents, but our analysis abstracts from this dimension. ${ }^{37}$ Finally, publicly provided health insurance naturally interacts with other government programs, such as disability insurance and welfare programs. It is important to investigate such an interaction for a better design of a health-care system.

$\overline{37}$ New research by Fang and Shephard (2015) is taking a step in this direction. 


\section{Appendix}

This appendix contains the supplementary materials for "Health-Care Reform or Labor Market Reform? A Quantitative Analysis of the Affordable Care Act." Appendix A provides detailed discussion of the related literature. Appendix B provides further details of the ACA. Appendix $\mathrm{C}$ discusses some of the key model assumptions. Appendices D and E provide details of calibration, in particular associated with the data from the CPS (Appendix D) and the MEPS (Appendix E). Appendix F provides the precise definition of the social welfare function employed in the paper. Appendix G provides a detailed analysis of the Massachusetts Health-Care Reform. Finally, Appendix H provides a sensitivity analysis, with respect to a higher elasticity of substitution between PT and FT labor inputs.

\section{A Detailed Discussion of the Related Literature}

Our paper contributes to five strands of literature. The first strand is the macroeconomic analysis of the health insurance system in the U.S. In this literature, a calibrated dynamic general equilibrium overlapping-generations model with medical expense shocks is usually used. Jeske and Kitao (2009) study the role of tax deductibility of employer-provided health insurance (EHI). Feng (2012) explores the macroeconomic effects of various reforms to the U.S. health insurance system. Hansen et al. (2014) study the effect of introducing an optional Medicare buy-in program for individuals close to retirement age.

The second strand of literature examines the implications and effects of previous health-care reforms in the U.S. Although there has not been sweeping health-care legislation since Medicare and Medicaid at the national level, several states have instituted reforms of their own. One prominent case is the 2006 Massachusetts Health-Care Reform Act. Research on the 2006 Massachusetts reform is closely related to our paper because the Massachusetts reform is considered the blueprint of the ACA. Therefore, studying what happened as a result of the Massachusetts reform could tell a lot about what we should expect from the ACA. Hackmann et al. (2015) compute the change in welfare from pre- to post-reform using changes in coverage, premiums, paid claims, and mandate penalty and conclude that the Massachusetts reform was welfare improving because it reduced adverse selection in the individual health insurance market in Massachusetts. Kolstad and Kowalski (2016) model and estimate the relationship between EHI and the labor market and find that the mandate-based health insurance reform is more efficient and thus achieves higher welfare than the tax-based reform. Using data from the Current Population Survey (CPS), Becker and Tüzemen (2015) argue that the increased availability of health insurance due to the Massachusetts health-care reform encouraged self-employment in the state. For the purposes of this paper, we consider 
only paid-employment and leave out self-employment. Garthwaite et al. (2014) show that there was a large increase in labor supply when Tennessee discontinued expansion of its Medicaid system in 2005. It is consistent with one of our key points that many individuals work mainly to keep subsidized health insurance through their employers. The opposite of this case may occur with the ACA because all individuals will be able to purchase affordable health insurance without employer participation. This might cause some individuals to leave employment and even the labor force.

The third strand of the literature studies macroeconomic and welfare effects of size-dependent distortionary policies. Because the employer mandate of the ACA affects only large firms, the ACA can be thought to include a type-dependent distortionary policy. The papers in the literature usually extend a model developed by Hopenhayn and Rogerson (1993). Restuccia and Rogerson (2008) show that distortions by size-dependent policies can account for the observed differences in total factor productivity across countries. Güner et al. (2008) study distortionary effects of policy favoring smaller firms, which is a widespread size-dependent policy.

Finally, our paper is closely related to the newly emerging literature that investigates the consequences of the ACA in various dimensions. Within the literature, many researchers use a calibrated/estimated structural model to evaluate the macroeconomic effects of the ACA. Pashchenko and Porapakkarm (2013) use a general equilibrium life-cycle model that incorporates both medical expenses and labor income risk and study the macroeconomic and welfare implications of the ACA. They find that the reform introduces two channels of redistribution, one from the healthy to the sick and the other from the rich to the poor, but welfare gains are largely due to welfare gains of low-income individuals. Compared with our paper, they abstract from the decision on the firms' side, and they do not have the margin between full-time (FT) and part-time (PT) employment, which is one of our focus points. Feng and Zhao (2014) use a similar model, but with an endogenous labor supply decision, and argue that the employment-based health insurance system (pre-ACA) is an important reason why Americans work more hours than do Europeans who obtain universal health insurance from their governments. Their paper does not model firms' decisions of health insurance provision either but is related to our paper in the sense that they focus on the distortions to the labor market that the U.S. health insurance system creates. Janicki (2011) also analyzes the ACA using a similar model but focuses on the role of asset testing. Jung and Tran (2016) introduce human capital accumulation and study the interaction between a decision on health insurance and human capital accumulation.

Unlike the papers listed above, our paper models the decisions on the firms' side. Brügemann and Manovskii (2010) and Aizawa and Fang (2013) model labor market search along with 
firms' coverage decisions before and after the implementation of the ACA. In this sense, these papers are the closest to ours. However, unlike these two studies, we distinguish between FT and PT employment. Our focus is on this specific distinction because lately there has been a lot of discussion on how the employer mandate incentivizes firms to shift their workforce from FT workers to PT workers to avoid paying health insurance premiums and penalties. Brügemann and Manovskii (2010) use a calibrated model with firm and worker heterogeneity and analyze the macroeconomic consequences of the ACA. They find that the ACA achieves universal coverage, but if the pooling of the individuals participating in the exchange is implemented without other elements of the ACA, the health insurance market suffers from adverse selection. We also confirm their finding. However, their paper does not have the margin between FT and PT employment, and they restrict their attention to positive analysis. Aizawa and Fang (2013) also study the effects of the ACA as well as various alternative health-care reforms, using a model with firm and worker heterogeneity and endogenous health. They also find that the uninsured rate declines significantly with the ACA. Interestingly, Aizawa and Fang (2013) find that if the employer mandate were removed from the ACA, the uninsured rate would be 6.44 percent, lower than the uninsured rate under the full ACA (7.27 percent). Without the employer mandate, the health composition of the workers in the health exchange pool is improved, which leads to a decrease in the premium in the exchange. This makes it less desirable for individuals to stay uninsured and subject to individual mandate penalty. We also find that the equilibrium under the policy of ACA without employer mandate achieves a higher average productivity, higher average wages and higher workers average utility, without increasing government spending. On the other hand, we find that removing the employer mandate from the ACA raises the uninsured rate, as less large firms would offer health insurance to their employees. Their paper also abstracts from the margin between FT and PT employment.

In terms of the question that we would like to answer, our work is closest to Mulligan (2014), which also considers the effect of the ACA on FT and PT employment. ${ }^{38}$ He argues that the ACA's employer penalty and the subsidies at the exchanges create FT employment taxes, which are avoided by PT workers and nonemployed individuals. FT workers are subject to these additional costs in two ways. If the employer does not offer health insurance, then the penalty to be paid by the employer is passed on to the FT worker as a wage reduction. If the employer offers health insurance, then the FT workers cannot receive subsidies at the exchanges, which he interprets as an implicit tax on FT employment. Mulligan constructs a general equilibrium model that is simpler compared to the model presented in this paper. He abstracts from heterogeneity in size across firms and workers' medical expenditures, but

38 This paper discusses the results in Chapter 6 of Mulligan (2015). 
allows for flexibility in adjusting work schedules, number of hours and weeks worked. Based on his model, the reform will likely reduce FT employment and lead to a shift from FT to PT employment for workers whose gains from subsidies are greater than the earnings lost when they move to PT employment. Along with this compositional shift, he estimates that the reform will reduce weekly employment by about 3 percent without reducing average weekly work hours per employee. ${ }^{39}$ We consider all components of the reform, while Mulligan (2014) focuses on the employer mandate and health insurance subsidies. Moreover, he does not take into consideration the size distribution of firms in the economy and that large firms have offered health insurance to their employees pre-ACA as well. Lastly, different from all the studies mentioned above, our paper considers the welfare effect of the ACA.

\section{B The Patient Protection and Affordable Care Act (ACA): De- tails}

The Patient Protection and Affordable Care Act (PPACA), or Affordable Care Act (ACA) for short, which was signed into law on March 23, 2010, is the most fundamental health reform legislation since the introduction of Medicare and Medicaid in 1965. Its main goal is to reduce the uninsured rate in the nation by expanding access to affordable health insurance for everyone. The ACA consists of five key components, an individual mandate (IM), establishment of the health insurance exchanges (EX), health insurance subsidies (SU), Medicaid expansion (ME), and an employer mandate (EM). The first four components affect individuals, while the employer mandate affects the employers. The majority of the components went into effect in January 2014, although the employer mandate has been mostly postponed. Moreover, there are some transitory measures, such as subsidies for small businesses that offer health insurance. Details of the main components are discussed below. ${ }^{40}$

\section{B.1 Individual Mandate}

The individual mandate requires every U.S. citizen or legal resident to have health insurance that qualifies as minimum essential coverage starting on January 1, 2014. ${ }^{41}$ The individual

\footnotetext{
${ }^{39}$ Even and Macpherson (2015) apply a difference-in-difference approach to the recent data from the CPS and find that involuntary part-time employment has been increasing since 2010, possibly due to employers' responses to the ACA. Their finding is consistent with Mulligan (2014).

${ }^{40}$ More detailed information can be found at http://www.healthcare.gov.

41 The essential health coverage includes at least the following items and services: ambulatory patient services (outpatient care individuals receive without being admitted to a hospital); emergency services; hospitalization (such as surgery); maternity and newborn care (care before and after a baby is born); mental health and substance use disorder services, including behavioral health treatment (this includes counseling and psychotherapy); prescription drugs; rehabilitation and rehabilitative services and devices (services and devices to help people with injuries, disabilities, or chronic conditions gain or recover mental and physical
} 
mandate doesn't change the way insurance is obtained. Individuals can still purchase health insurance from private providers (PHI), obtain employer-provided health insurance (EHI), or obtain insurance through a government program such as Medicaid or Medicare. If an individual chooses to be uninsured, she is required to pay a penalty that is either $\$ 95$ per person or 1 percent of the individual's annual income in 2014, whichever number is higher. The penalty will be gradually increased until 2016, at which time the fee will be either $\$ 695$ per person or 2.5 percent of the individual's annual income, whichever is higher. ${ }^{42}$

\section{B.2 Health Insurance Exchange}

The ACA mandates creation of state-based marketplaces (exchanges) through which individuals can purchase health insurance. Each state is allowed to choose whether to manage its own exchange or defer to the federal management. ${ }^{43}$ The exchanges opened up on October 1, 2013, for individuals to purchase health insurance starting from the beginning of 2014, when the individual mandate took effect. On these exchanges, all individuals can shop for different plans based on cost and coverage. Plans are presented in five categories: bronze, silver, gold, platinum, and catastrophic, to make comparison easier. Cost assistance, which includes tax credits and cost-sharing subsidies, is available through the exchanges and can be used only for health insurance purchased at the exchanges. We come back to subsidies below.

The ACA also mandates new regulations to the private insurance market, most notably removing the previous practice of denying coverage or charging higher rates for people with pre-existing conditions. The law establishes a medical loss ratio and reviews for premium rate increases. Insurance companies are no longer allowed to discriminate against customers by charging higher premiums based on gender or health status. However, certain factors such as age, tobacco use, family size, and geography can be used to determine insurance costs to consumers. As for age, health insurance premium rates cannot vary by more than 3:1 for individuals who are similar except for their age. As for tobacco use, the rates cannot vary more than $1.5: 1$ for similar individuals.

\footnotetext{
skills); laboratory services; preventive and wellness services; chronic disease management; and pediatric services.

42 There are some exceptions for financial hardship, religious objections, individuals of American Indian descent, and individuals who have been uninsured for less than three months.

${ }^{43}$ States that set up their own exchanges determine which providers can participate in their exchange and negotiate benefits and prices. In a federal exchange, the U.S. Department of Health and Human Services (HHS) makes these decisions. In a joint-run exchange, any provider that meets the minimum federal and state requirements can compete.
} 


\section{B.3 Health Insurance Subsidies}

In order to assist individuals in purchasing health insurance, the ACA provides a number of subsidies for individuals and families with incomes between 100 percent and 400 percent of the federal poverty level (FPL) when they purchase health insurance on the health insurance exchanges. The FPL was $\$ 11,670$ for an individual and $\$ 23,850$ for a family of four in 2014 . However, if the income is below 133 percent of the FPL, the individual is eligible for Medicaid, meaning that the individual who takes Medicaid does not need to pay for health insurance premiums. The subsidies are provided in the forms of tax credit or cost-sharing. The amount of the credit varies with income, guaranteeing that the monthly premium is capped between 2 and 9.5 percent of total income of individuals or families. In particular, if the current income of an individual is at 400 percent of the FPL, she does not need to pay more than 9.5 percent of her income for health insurance premiums. The difference is subsidized by the government. If her income is between 100 percent and 133 percent, the maximum health insurance premium that the individual is liable for is 2 percent. The maximum health insurance premium that the individuals or families whose income is between 100 and 400 percent of the FPL have to pay gradually increases between 3 percent and 9.5 percent of their income. Tax credits can be paid in advance to lower the premium upfront (this is called an advanced premium tax credit) or can be deducted from federal income taxes at the end of the year. Individuals with an option to obtain EHI are not eligible for health insurance subsidies. Cost-sharing reduction subsidies lower out-of-pocket costs (deductibles, coinsurance, copayments, and prescriptions) for silver plans bought on an exchange and are offered to individuals and families with incomes between 100 and 250 percent of the FPL.

\section{B.4 Medicaid Expansion}

Pre-ACA, Medicaid provided free or low-cost care for low-income individuals and families with children, pregnant women, and people with disabilities. Although the purpose of the ACA was intended for every state to expand Medicaid coverage to all individuals whose income is below 133 percent of the FPL, a Supreme Court ruling gave states an option to decline the expansion. ${ }^{44}$ As a result, only 30 states and the District of Columbia have accepted the expansion. ${ }^{45}$ The states that did not adopt the expansion have retained their pre-ACA

\footnotetext{
${ }_{44}^{4}$ The threshold is also often denoted as 138 percent because of how income is defined under the ACA.

45 The states that have currently accepted Medicaid expansion are Alaska, Arizona, Arkansas, California, Colorado, Connecticut, Delaware, Hawaii, Illinois, Indiana, Iowa, Kentucky, Maryland, Massachusetts, Michigan, Minnesota, Montana, Nevada, New Hampshire, New Jersey, New Mexico, New York, North Dakota, Ohio, Oregon, Pennsylvania, Rhode Island, Vermont, Washington, and West Virginia. Utah is still debating.
} 
eligibility criteria for Medicaid and the Children's Health Insurance Program (CHIP). ${ }^{46}$ Unemployed individuals in some states may qualify for Medicaid and/or CHIP, or they may benefit from subsidized premiums at the exchanges.

Whether a state decides to expand Medicaid is very important because of the "coverage gap." Pre-ACA, there were some states where Medicaid eligibility was as low as 50 percent of the FPL, and factors such as gender and pregnancy affected eligibility. The coverage gap occurs when a state opts out of Medicaid expansion, which makes some individuals and families with incomes below 100 percent of the FPL, and therefore ineligible for health insurance subsidies, also ineligible for Medicaid. According to a report by the Kaiser Family Foundation, nearly four million poor, uninsured adults will fall into the coverage gap. These individuals would have been newly eligible for Medicaid had their state allowed for Medicaid expansion. ${ }^{47}$

\section{B.5 Employer Mandate}

The employer mandate requires all large firms (those with 50 or more full-time equivalent (FTE) employees) to provide health insurance to the FT employees and their dependents up to 26 years of age or pay a penalty. Under the ACA, all employees working more than 30 hours per week are considered FT employees, while those working fewer than 30 hours per week are considered PT employees. ${ }^{48}$ To calculate the number of FTE employees, the total of monthly PT hours are divided by 120 and added to the number of FT workers. Firms with 100 or more FTE employees are required to insure at least 70 percent of their FT workers by 2015. Firms with 50 or more FTE employees will need to start offering insurance to at least 95 percent of their FT workers by 2016.

If a firm doesn't provide health insurance coverage, provides coverage that doesn't offer minimum essentials, or provides coverage that is unaffordable, then the firm has to pay a penalty, called "employer shared responsibility payment." 49 The penalty is charged peremployee and on a per-month basis. If no health insurance is provided, then the annual

$\overline{46}$ The CHIP program provides free or low-cost coverage to children and other family members. Children whose parents have too much income to qualify for Medicaid can qualify for CHIP.

${ }^{47} \mathrm{See} \quad$ http://kff.org/health-reform/issue-brief/the-coverage-gap-uninsured-poor-adults-in-states-that-donot-expand-medicaid-an-update/.

48 Notice that employment size as measured by FTE does not change when a FT employee works more than 30 hours per week. However, longer hours by a PT worker may increase the firm's employment size if the hours worked exceed 30. Therefore, there is a concern that employers may choose to have their FT employees work longer hours. This margin is abstracted from our analysis.

${ }^{49}$ A health insurance coverage is considered unaffordable if an employee's share of the premium costs for employee-only coverage is more than 9.5 percent of her yearly household income and if the plan's share of the total costs of covered services is less than 60 percent. 
payment is $\$ 2,000$ per FT employee excluding the first 30 employees. If health insurance is provided but the insurance doesn't meet the minimum requirements, the fee is either $\$ 3,000$ per FT employee receiving subsidies or $\$ 2,000$ per FT employee (minus the first 30 employees), whichever is less. Unlike employer contributions to employee premiums, the employer shared responsibility payment is not tax deductible.

Small firms, those with fewer than 50 FTE employees, are exempt from the penalty. Moreover, a small firm may qualify for subsidies called the small business health-care tax credit if the firm offers health insurance to its employees. However, it is a temporary measure. Small employers could claim the credit through 2013 and for two consecutive years beginning in 2014. Not much attention has been paid to this small business tax credit program, probably because it is a temporary measure, and the take-up rate has been low. The Government Accountability Office (2012) (GAO) reports that, although 1.4 to 4 million businesses are estimated to be eligible for the tax credit, only 170,300 small employers claimed the tax credit in 2010. The GAO concludes that the small amount of benefits (most businesses were not able to claim the full benefits due to adjustments based on average wages), and the administrative burden contributed to the low take-up.

A small employer is eligible for subsidies if it has fewer than 25 FTE employees making an average of about $\$ 50,000$ a year or less. Firms with 10 or fewer FTE employees with average annual wages of less than $\$ 25,000$ qualify for the full credit of up to 50 percent of their share of employer premiums. ${ }^{50}$ If a firm hires more than 10 employees but fewer than 25 employees, the amount of tax credit is reduced by $1 / 15$ th for each employee over 10 . If the average annual wages of a firm are more than $\$ 25,000$ but less than $\$ 50,000$, the amount of tax credit is reduced by $1 / 25$ th for each $\$ 1,000$ in average annual wages over $\$ 25,000$. To obtain the tax credit, the firm needs to pay at least half of the total premium cost or half of a benchmark premium (second lowest cost silver plan). Starting in 2014, the tax credit became available only when the firm offered coverage through the Small Business Health Options Program (SHOP), which is a new program that simplifies the process of buying health insurance for small businesses. Beginning in 2016, all SHOPs will be open to firms with up to 100 FTE employees.

\section{B.6 Summary: Timeline of the ACA}

As we discuss above, some mandates of the reform have been gradually implemented. We provide a timeline below to summarize the changes taking place because of the main com-

50 This is for for-profit employers. Full credit for a tax-exempt employer is 35 percent of the health insurance premiums paid by the employer. 
ponents of the ACA that are relevant to our paper. ${ }^{51}$

Starting on January 1, 2014:

- All individuals are required to pay a penalty that is either $\$ 95$ per person or 1 percent of the individual's annual income, whichever number is higher.

- Health insurance exchanges open up (in October 2013) for individuals to purchase subsidized health insurance for 2014.

- Health insurance premium and cost-sharing subsidies become available at the exchanges.

- Medicaid is expanded in states that accepted the expansion.

- The law brings new regulations to the private insurers, such as guaranteed availability of insurance, community rating, and no pre-existing conditions.

Starting in January 1, 2015:

- All individuals are required to pay a penalty that is either $\$ 325$ per person or 2 percent of the individual's annual income, whichever number is higher.

- Firms with 100 or more FTE employees are required to insure at least 70 percent of their FT workers.

Starting in January 1, 2016:

- All individuals are required to pay a penalty that is either $\$ 695$ per person or 2.5 percent of the individual's annual income, whichever number is higher.

- Firms with 50 or more FTE employees are required to insure at least 95 percent of their FT workers.

\section{Discussion of Some Assumptions of the Model}

In this section, we discuss six important assumptions. First, we abstract from saving. Of course, with risk-averse preferences, workers would like to save and self-insure if allowed. However, the model is already rich, and it is unfeasible to solve a model with a saving decision on top of what we already have in the model. Relaxing this assumption is definitely

51 There are many more changes associated with the reform. For further information, see http://www.hhs.gov/healthcare/about-the-law/index.html. 
interesting. Both Aizawa and Fang (2013) and Brügemann and Manovskii (2010) assume hand-to-mouth workers as well.

Second, a related assumption is that firms are owned by capitalists who consume dividends every period. It would definitely be interesting to have realistic inequality in income and wealth holdings so that we could discuss redistribution in a more realistic manner.

Third, firms offer health insurance only to FT employees. This simplifies the firms' decisions. Firms benefit economically by providing health insurance for workers. For example, offering health insurance may help employers recruit and keep high-quality workers. Offering health insurance may also contribute to productivity by reducing absenteeism and turnover. According to the MEPS data from 2004 to 2006, only 30 percent of the PT employees who worked at private-sector establishments offering health insurance were eligible for obtaining health insurance, and of these employees only about half of them enrolled in health insurance. As such, we make the simplifying assumption that PT workers are not obtaining EHI in the model. We think it is not the first-order concern because many PT workers did not obtain health insurance from their employers in the pre-ACA period, and the ACA does not obligate large firms to offer health insurance to PT workers.

Fourth, there are spot labor markets, and as a result, all firms have the same composition of heterogeneous workers. In both Aizawa and Fang (2013) and Brügemann and Manovskii (2010), heterogeneity in the employees' health across different firms plays an important role. We abstract from this feature so that we can introduce richer heterogeneity in other dimensions, such as FT and PT employment.

Fifth, we focus on individuals in the labor force. This assumption is related to the fact that we abstract from life after retirement and dependents. Introducing these features in an analysis of the ACA would definitely be an interesting path.

Sixth, we assume that the distribution of medical expense shocks is exogenous. This is for simplicity. In particular, some studies argue that being insured improves health in general because access to preventive care is cheaper if an individual is insured. This feature is expected to increase the benefits of the ACA if the ACA achieves a lower uninsured rate in the nation.

\section{Calibration Details: CPS (ASEC)}

The Current Population Survey (CPS), sponsored jointly by the U.S. Census Bureau and the U.S. Bureau of Labor Statistics (BLS), is the primary source of labor force statistics for the population of the United States. Every month, 60,000 households are surveyed to collect information on a representative population's demographic characteristics and detailed labor force status. Although the monthly CPS does not have any information about workers' health 
Table 13: Life-Cycle Statistics: CPS ${ }^{1,2}$

\begin{tabular}{lrrrr}
\hline \hline Age (years) & $16-64$ & $16-25$ & $26-54$ & $55-64$ \\
\hline Proportion & 100.00 & 21.51 & 66.61 & 11.88 \\
\hline Employment Status & & & & \\
Full-time (FT) employed & 79.17 & 54.53 & 86.55 & 82.44 \\
Part-time (PT) employed & 15.19 & 32.87 & 9.92 & 12.74 \\
Unemployed & 5.64 & 12.60 & 3.53 & 4.82 \\
\hline Health Insurance & & & & \\
Employer-provided health insurance (EHI) & 56.16 & 27.06 & 63.81 & 65.95 \\
Private health insurance (PHI) & 14.49 & 26.71 & 10.38 & 15.44 \\
Medicaid & 6.69 & 10.47 & 5.58 & 6.09 \\
Uninsured & 22.65 & 35.76 & 20.23 & 12.51 \\
\hline \hline
\end{tabular}

${ }^{1}$ Source: The Current Population Survey Annual Social and Economic Supplement, average statistics for 2004 to 2006.

2 The following adjustments were made to make the data consistent with the model: (i) FT workers receiving EHI as dependents are reclassified as FT-EHI policyholders, (ii) individuals receiving PHI as dependents are reclassified as PHI policyholders, (iii) individuals working PT or who are unemployed and receiving EHI either as a policyholder or a dependent are reclassified as PHI policyholders, and (iv) individuals receiving other public HI are reclassified as individuals receiving Medicaid.

insurance status, there is an annual supplement called the Annual Social and Economic Supplement (ASEC) that collects additional information from a set of CPS respondents about sources of income, earnings, and health insurance during the previous calendar year. The CPS (ASEC) data allow us to obtain the insurance rate among the private-sector employees. There are four types of insurance: Medicaid, other types of public insurance (Medicare, veterans insurance), employer-provided private health insurance (EHI), and directly purchased private health insurance (PHI). Some individuals report having several types of insurance; in that case, we adjust their survey weights by dividing the number of insurance types they have. Some individuals report having Medicaid and PHI; we drop their Medicaid insurance if they also report annual incomes above $\$ 50,000$.

We use 2004 to 2006 averages of the CPS (ASEC) data to create calibration targets for the baseline model. We chose these three years because during this time there were no recessions and no discussion of a national health-care reform. We include all workers 16 to 64 years of age in the labor force. The age cutoff is at 64 years because we do not have retirement in the model. We also exclude those who were employed in agriculture or in the military. We restrict our sample to the private sector, meaning employed individuals are currently working 
in private-sector jobs and unemployed individuals held their last jobs in the private sector. We chose to focus on the private sector because we are interested in understanding how the changes associated with the ACA may affect the decisions made by the firms and individuals in the private sector. Individuals working 10 to 34 hours are considered PT employees, and those working 35 hours or more are considered FT employees, which is consistent with the definition of FT and PT work pre-ACA.

We divide workers that satisfy the criteria into three age groups - young workers (16-25 years of age), prime-age workers (26-54 years of age), and old workers (55-64 years of age). We focus on these three groups because each group has distinct characteristics: (1) young workers tend to work PT and have lower incomes but have medical expenditure risks that are smaller; (2) prime-age workers tend to exhibit strong labor market attachment, typically working FT, and have higher incomes but have medical expense risks that are also higher; and (3) old workers tend to work FT less frequently than prime-age workers but have higher medical expense risks.

Table 13 summarizes some statistics from the CPS (ASEC). About 21.5 percent of the labor force are young workers, 66.6 percent are prime age, and 11.9 percent are old workers. The overall unemployment rate is 5.6 percent, which is used as a calibration target. The unemployment rate is higher for young workers (12.6 percent) than prime-age workers (3.5 percent) and old workers (4.8 percent). In the labor force, 79.2 percent work FT, while 15.2 percent work PT. This allocation also varies across age groups. Among young workers, 32.9 percent work PT, while this ratio is lower for prime-age workers (9.9 percent) and old workers (12.7 percent).

Regarding the health insurance-related statistics, to make the statistics from the CPS (ASEC) consistent with the model, we need to make some adjustments for three reasons. First, there are no dependents in the model. Second, we assume PT workers do not receive health insurance from their employers, although some PT workers do in the data. Third, there are public health insurance programs other than Medicaid that are not included in the model. To account for these differences, we make adjustments to the CPS (ASEC) data so that the data are consistent with the model, making sure we do not drop workers or the unemployed out of the sample. We decided to keep all individuals in the labor force when computing the statistics because we would like to keep the same aggregate uninsured rate as in the data. Four adjustments that we made are as follows:

1. FT workers receiving EHI from an employer as dependents are reclassified as FT workers receiving EHI from their employers as policyholders.

2. Workers receiving directly purchased PHI as dependents are reclassified as workers 
purchasing PHI as policyholders.

3. Unemployed or PT workers receiving EHI either as policyholders or dependents are reclassified as purchasing PHI as policyholders.

4. Workers receiving other public health insurance are reclassified as workers receiving Medicaid.

The last four rows of Table 13 show the insurance choices of workers after making the adjustments listed above. All are divided by the number of individuals in the labor force. Overall, 56.2 percent of the individuals in the labor force receive EHI as FT workers, 14.5 percent purchase PHI, and 6.7 percent receive Medicaid. The uninsured rate, which is the remaining part of the labor force, is 22.7 percent. However, one can see that there is significant heterogeneity across age groups. For example, young workers have a higher uninsured rate (35.8 percent). They also rely more on PHI (26.7 percent) as well as Medicaid (10.5 percent). Prime-age workers have a slightly lower uninsured rate (20.2 percent). They rely more on EHI (63.8 percent) and less on PHI (10.4 percent) or Medicaid (5.6 percent). The uninsured rate is significantly lower for older workers (12.5 percent) because more of them obtain EHI (66.0 percent) and PHI (15.4 percent).

\section{E Calibration Details: Medical Expenditure Panel Survey}

In this section, we describe how we construct medical expense shocks using the Medical Expenditure Panel Survey (MEPS). ${ }^{52}$ We use the MEPS Longitudinal Data for 2004 and 2005. We include only individuals whose wage incomes were positive in both 2004 and 2005 and who were between 16 and 64 years of age. We document statistics for all individuals who satisfy the criteria and consider young workers (16-25 years of age), prime-age workers (26-54 years of age), and old workers (55-64 years of age) separately.

Table 14 summarizes some statistics that are of interest to us. The first row shows the proportion of each age group. These numbers are generally consistent with the numbers from the CPS (ASEC) presented in Table 13. The next two rows show the means and medians of the wage income. The median wage income was $\$ 30,000$ for the whole sample. However, it was lower for young workers $(\$ 13,131)$ and higher for older groups $(\$ 32,500$ for prime-age workers and $\$ 33,500$ for old workers). The means are higher because the distributions are skewed to the right for each age group.

The bottom panel shows the statistics for the distribution of medical expenses in 2005. The mean and median are $\$ 2,638$ and $\$ 730$, respectively, but there is a large dispersion within and

\footnotetext{
52 We would like to thank Sagiri Kitao for letting us use her cleaned-up MEPS data for 2009 to 2010 in an earlier draft.
} 
Table 14: Life-Cycle Statistics: The MEPS ${ }^{1}$

\begin{tabular}{lrrrr}
\hline \hline Age (years) & $16-64$ & $16-25$ & $26-54$ & $55-64$ \\
\hline Proportion (\%) & 100.00 & 15.91 & 69.72 & 14.37 \\
\hline Wage & & & & \\
Wage income, mean & 36,409 & 16,202 & 39,922 & 41,733 \\
Wage income, median & 30,000 & 13,131 & 32,500 & 33,500 \\
\hline Medical Expense Distribution & & & & \\
Medical expense, mean & 2,638 & 1,498 & 2,429 & 4,913 \\
Medical expense, median & 730 & 374 & 669 & 2,026 \\
Standard deviation & 7,495 & 3,953 & 6,871 & 11,733 \\
Proportion of zero expenditure (\%) & 18.67 & 25.13 & 19.14 & 9.28 \\
90th percentile & 6,073 & 3,828 & 5,481 & 9,894 \\
99th percentile & 27,613 & 14,086 & 25,788 & 48,765 \\
\hline \hline
\end{tabular}

across age groups. Among all workers, even though the median is only $\$ 730$ and 18.7 percent pay nothing, the standard deviation is $\$ 7,495$, and the 99 th percentile of the medical expense distribution pays $\$ 27,613$. In terms of across-age-group heterogeneity, both the average of and the dispersion of medical expenses increase with age. The median medical expense is only $\$ 374$ among young workers, but it is $\$ 2,026$ among old workers. The standard deviation also increases with age, from $\$ 3,953$ for the young to $\$ 6,871$ for the prime age and $\$ 11,733$ for the old. The 99th percentile among young workers pays $\$ 14,086$, while the 99 th percentile among old workers pays $\$ 48,765$.

We create a medical expense shock based on the longitudinal data from the MEPS in the following manner.

1. We create grid points $x_{1}, x_{2}, \ldots, x_{N}$ for medical expense shocks. ${ }^{53}$ We set $x_{1}=0$ because there are a significant number of workers who pay zero each year.

2. We construct the Markov transition matrix, $\pi_{i, x, x^{\prime}}$, using the following three steps:

(a) First, we compute the probability that a worker of age group $i$ whose medical expenses were not zero in 2004 had zero medical expenses in 2005. We assign the probability of $\pi_{i, x_{n}, x_{1}}$ with $n=2,3, \ldots, N$.

\footnotetext{
${ }^{53}$ We create the grids based on the method of Tauchen (1986) applied to workers 55 to 64 years of age because they exhibit the largest range of medical expenses.
} 
(b) Second, we compute the probability that a worker of age group $i$ whose medical expenses were zero in 2004 and had zero medical expenses in 2005. We assign the probability of $\pi_{i, x_{1}, x_{1}}$.

(c) Using only workers of age group $i$ who report strictly positive medical expenses in both 2004 and 2005, we estimate the following AR(1) process:

$$
\log x_{2005}=\left(1-\rho_{x, i}\right) \mu_{x, i}+\rho_{x, i} \log x_{2004}+\epsilon^{\prime} \quad \epsilon^{\prime} \sim N\left(0, \sigma_{x, i}^{2}\right)
$$

Then we approximate the estimated $\mathrm{AR}(1)$ process with a discrete first-order Markov process using the method of Tauchen (1986). After taking into account the probability of zero medical expenses, the Markov process gives $\pi_{i, x_{n}, x_{m}}$ with $n=2,3, \ldots, N$ and $m=2,3, \ldots, N$.

3. As for $\pi_{i, x_{1}, x_{n}}$ with $n=2,3, \ldots, N$, we assume that if the medical expenses are zero in the current period but are not zero in the next period, medical expenses are distributed according to the ergodic distribution of the Markov process obtained in the previous step.

\section{F Details of Welfare Analysis}

For our welfare analysis, we use ex-ante expected lifetime utility of a newborn in the steady state of the model. In evaluating the welfare, we convert the welfare in an alternative model (for example, the post-ACA model) by computing the consumption equivalence variation $(\mathrm{CEV})$, which is the percentage change in consumption in each period and state to make welfare in the baseline model (pre-ACA) equal to the welfare in the post-ACA model. If the CEV is positive (negative), a newborn is better off (worse off) by being born into the steady state of the post-ACA model. This is a common criterion used in macroeconomics with heterogeneity. ${ }^{54}$ To be more specific, the CEV associated with transitioning from the baseline model pre-ACA to the model post-ACA can be implicitly characterized as follows:

$$
\int V^{\mathrm{BASE}}(1, d, x, s, e) d \mu_{1, d, x, s, e}^{\mathrm{BASE}}+\log (1+C E V)=\int V^{\mathrm{ACA}}(1, d, x, s, e) d \mu_{1, d, x, s, e}^{\mathrm{ACA}},
$$

$V^{\mathrm{BASE}}(1, d, x, s, e)$ and $V^{\mathrm{ACA}}(1, d, x, s, e)$ are the values of a newborn $(i=1)$ in the baseline pre-ACA model and the post-ACA model, respectively. $\mu_{1, d, x, s, e}^{\mathrm{BASE}}$ is the type distribution of newborns $(i=1)$ in the baseline model. This is basically the type distribution of age-1 workers and is the same as the type distribution of newborns by assumption. $\mu_{1, d, x, s, e}^{\mathrm{ACA}}$ is the type distribution of newborns in the model post-ACA. Notice the term $\log (1+C E V)$.

${ }^{54}$ For example, see Conesa et al. (2009). 
This term can be separated from the rest of the left-hand side because the utility from consumption is assumed to take a log form, and thus the CEV, which is the growth rate of consumption in each period and state, can be separated out from the representation of the lifetime utility. $C E V=0$ means the newborn's ex-ante expected lifetime utility is equalized between the baseline model pre-ACA and the model post-ACA.

\section{G Analysis of the Massachusetts Health-Care Reform}

As we will discuss below, there are a lot of similarities between the ACA, which is the main focus of this paper, and the Massachusetts Health-Care Reform. Indeed, the latter is often cited as the blueprint for the former. In this section, we implement a stylized version of the Massachusetts Health-Care Reform within our model and study the health insurance and labor market consequences. One advantage of studying the Massachusetts reform is that the reform was implemented starting in 2007, and thus we have data and know more about the consequences of the Massachusetts reform than we do about the ACA.

In Section G.1, we provide details about the Massachusetts Health-Care Reform. In Section G.2, we compare the data in Massachusetts on the labor market and health insurance decisions before and after the Massachusetts Health-Care Reform. Finally, in Section G.3, we implement the stylized version of the Massachusetts Reform and investigate the reform's implications by comparing the model's implications with the data since the reform was implemented in 2007. We also compare the key statistics among the calibrated baseline model, the model with the ACA, and the model with the Massachusetts Health-Care Reform.

\section{G.1 Massachusetts Health-Care Reform: Details}

In 2006, a comprehensive health-care reform legislation was passed in Massachusetts. The law overhauled much of the existing health-care system in the state. The Massachusetts Health-Care Reform's key components were (i) an individual mandate, (ii) formation of a state health insurance exchange, (iii) subsidies at the exchange, (iv) Medicaid expansion, and (v) an employer mandate. Below we discuss details of each component.

The individual mandate required all residents of the state to obtain some form of health insurance or pay a penalty of up to 50 percent of the lowest cost premium they would have qualified for on the state's health insurance exchange, called the Connector. Individuals with no access to employer-provided health insurance (EHI) could obtain coverage through the Connector. Individuals with incomes up to 150 percent of the FPL received no penalty, but penalties for those with incomes above 150 percent of the FPL were indexed to their incomes. Health insurance was filed on tax returns.

Launched in 2007, the Connector allowed individuals to shop online for health insurance that 
met the minimum requirements dictated by the Health Reform Act. The Connector offered both subsidized and nonsubsidized plans for those who did not have access to health insurance through their families or employers. ${ }^{55}$ Subsidized insurance options were offered through the Commonwealth Care Health Insurance Program (Care) and nonsubsidized insurance was offered through the Commonwealth Choice Health Insurance Program (Choice). Care was a subsidized insurance program available to adults earning up to 300 percent of the FPL (\$10,210 for an individual in 2007) who did not have access to EHI or other subsidized insurance and who met additional eligibility criteria. Fully subsidized health insurance was provided to individuals with incomes up to 150 percent of the FPL. Care provided subsidized private health coverage on a sliding scale: Individuals with incomes below 150 percent of the FPL were eligible for fully subsidized coverage. For those with incomes between 150 percent and 300 percent of the FPL, individual monthly premiums ranged between $\$ 39$ and $\$ 116$.

Even before the implementation of the health-care reform, Massachusetts imposed various restrictions to the private health insurance market, such as community rating and guaranteed issuance. At the time of the reform, Massachusetts had a 2:1 maximum age rating ratio compared with a 3:1 ratio of the ACA. The main purpose of the more strict restriction was to keep health insurance premiums low for old workers. Massachusetts also prohibited premiums from varying based on tobacco use.

Massachusetts also expanded Medicaid and other public health insurance programs, mostly for children and their parents. Medicaid was expanded for children with family incomes up to 300 percent of the FPL, for parents with incomes up to 133 percent of the FPL, for pregnant women with incomes up to 200 percent of the FPL, and for long-term unemployed individuals with incomes up to 100 percent of the FPL.

The last component of the reform was an employer mandate, which required employers with more than 10 full-time equivalent (FTE) employees to provide health insurance to their FT employees who worked 35 hours or more a week. Employers could offer a standard group plan to their employees and contribute to the premium costs. Alternatively, they could pay an "employer fair share contribution," which was essentially a tax of up to $\$ 295$ per employee. Employers were additionally required to let their employees pay their insurance premiums with pre-tax dollars. The employer mandate took effect on July 31, 2007, but was repealed

\footnotetext{
55 The Massachusetts Health Connector Board, by the Authority of the Massachusetts Health-Care Reform, determined which plans provided by various insurers were offered for purchase on the Connector. Insurance providers presented to the board relevant information about the cost and coverage of their plans. The board then decided which of these plans to offer on the Connector for Commonwealth Choice. The plans were designated as Gold, Silver, or Bronze based on their actuarial values. A fourth level, Young Adult Plans, was created exclusively for young adults 19 to 26 years of age and offered a narrower benefits package. For more info, see http://www.commonwealthfund.org.
} 
in July 2013 to better facilitate the transition to the requirements of the national health-care reform.

Although there are many similarities between the Massachusetts reform and the ACA, there are a few important differences. The penalties for firms that fail to comply are much larger under the ACA than under the Massachusetts reform, but fewer firms are likely to be affected under the ACA. The Massachusetts reform defined FT work as 35 hours or more per week, while the ACA changes it to 30 hours or more per week. In the ACA, the employer mandate applies to firms with 50 or more FTE employees. In comparison, in Massachusetts, employers with 11 or more employees were required to provide health insurance to FT workers. Firms that failed to comply were required to pay a penalty of $\$ 295$ per employee in Massachusetts; this penalty is much larger for firms under the ACA $(\$ 2,000$ per FT employee after the first 30 FT employees). Similarly, penalties for individuals who do not obtain health insurance are larger under the ACA (\$695 annually or 2.5 percent of annual income by 2016) compared with the Massachusetts reform (up to 50 percent of the lowest cost premium they would have qualified for under the Connector in 2008).

Another difference between the two reforms is the extent of expansion in public health insurance programs and subsidies. The reform in Massachusetts primarily expanded Medicaid for children and their parents and offered fully subsidized coverage for those with incomes below 150 percent of the FPL. Individuals with incomes between 150 percent and 300 percent of the FPL were eligible to receive subsidies. In comparison, the ACA offered states federal funding to expand Medicaid to all individuals with incomes below 133 percent of the FPL and extended subsidized coverage for individuals with incomes up to 400 percent of the FPL. Although the national reform gives subsidies to more families, Massachusetts reform was more generous in fully subsidized coverage.

\section{G.2 Massachusetts Health-Care Reform: Changes After the Reform}

Table 15 compares the distribution of FT employed, PT employed, and unemployed for the overall labor force as well as the three age groups. The top panel presents the pre-reform (2000-2005) averages from the CPS (ASEC) and the bottom panel shows post-reform (20072012) averages. With these time periods, we aim to present a longer-run view of the changes in Massachusetts. Using a longer time series helps us overcome the issue that arises from the relatively small number of individuals observed in the CPS (ASEC), because we consider only the individuals in Massachusetts.

The first column shows the percentages from the entire labor force (16-64 years of age). Before the reform, 76.1 percent of the labor force worked FT, while 17.8 percent worked PT. The remaining 6.1 percent were unemployed during 2000-2005. In the six years following 
Table 15: Pre-Reform vs. Post-Reform: Labor Market Outcomes ${ }^{1}$

\begin{tabular}{lrrrr}
\hline \hline & All & Young & Prime Age & Old \\
\hline Pre-reform (2000-2005) & & & & \\
Full-time (FT) employed & 76.12 & 49.10 & 83.26 & 79.85 \\
Part-time (PT) employed & 17.73 & 33.54 & 13.34 & 16.87 \\
Unemployed & 6.14 & 17.36 & 3.40 & 3.28 \\
\hline Post-reform (2007-2012) & & & & \\
Full-time (FT) employed & 73.00 & 43.50 & 81.54 & 75.41 \\
Part-time (PT) employed & 18.10 & 36.46 & 13.09 & 15.22 \\
Unemployed & 8.89 & 20.03 & 5.37 & 9.37 \\
\hline \hline
\end{tabular}

${ }^{1}$ Source: Current Population Survey Annual Social and Economic Supplement.

the reform, there have been small shifts in the composition of employment in the state. The share of PT employment rose to 18.1 percent, while the share of FT employment declined modestly to 73.0 percent. Meanwhile, the average unemployment rate was 8.9 percent in the post-reform period, which likely reflects the effects of the Great Recession. Certain patterns remain unchanged after the reform, such as (i) the proportion of FT employment is highest among prime-age workers, and (ii) the proportion of PT work is the highest among young workers. However, (iii) the unemployment rate is the lowest among prime-age workers in the post-reform period, while it was lowest among older workers in the pre-reform period. Table 16 compares the choices regarding health insurance in Massachusetts in the pre-reform (top panel) and post-reform periods (bottom panel). There are five major changes to discuss: (i) The uninsured rate dropped from 16.5 percent in 2000 to 2005 to 10.1 percent in 2007 to $2012,{ }^{56}$ (ii) insurance enrollment increased for all age groups, but mostly for young and old workers, and (iii) the share of workers obtaining Medicaid almost doubled, from 6.9 percent pre-reform to 12.8 percent post-reform. Enrollment increased for all age groups. For prime-age and old workers, enrollment in Medicaid more than doubled after the reform, and this corresponded to a shift from uninsurance. (iv) The proportion of workers with PHI increased slightly from 16.7 percent in 2000 to 2005 to 18.6 percent in 2007 to 2012 . The change was mostly due to increased enrollment of young workers in PHI. (v) Interestingly, the proportion of workers with EHI declined modestly from 59.9 percent in 2000 to 2005 to 58.6 percent in 2007 to 2012. The share of workers with EHI dropped for all age groups but mostly among old workers.

\footnotetext{
56 The average uninsured rate for 2007 to 2008 was 10.7 percent, showing that the drop in the uninsured rate happened right after the implementation of the reform.
} 
Table 16: Pre-Reform vs. Post-Reform: Health Insurance Choices ${ }^{1}$

\begin{tabular}{lrrrr}
\hline \hline & All & Young & Prime Age & Old \\
\hline Pre-reform (2000-2005) & & & & \\
Employer-provided health insurance (EHI) & 59.88 & 29.23 & 67.29 & 68.24 \\
Private health insurance (PHI) & 16.70 & 30.41 & 12.61 & 17.66 \\
Medicaid & 6.89 & 11.60 & 5.97 & 4.38 \\
Uninsured & 16.52 & 28.76 & 14.13 & 9.73 \\
\hline Post-reform (2007-2012) & & & & \\
Employer-provided health insurance (EHI) & 58.55 & 28.50 & 66.29 & 65.40 \\
Private health insurance (PHI) & 18.59 & 37.05 & 13.09 & 17.79 \\
Medicaid & 12.75 & 18.09 & 11.42 & 11.33 \\
Uninsured & 10.11 & 16.36 & 9.20 & 5.48 \\
\hline \hline
\end{tabular}

${ }^{1}$ Source: Current Population Survey Annual Social and Economic Supplement. As for the adjustments to make data consistent with the model, see Section D.

\section{G.3 Massachusetts Health-Care Reform: Model Experiment}

In the model, we introduce the stylized version of the Massachusetts Health-Care Reform, which consists of the following six components:

1. Individual mandate: Workers have to obtain health insurance or pay a penalty of $0.5 q_{1}$.

2. Health insurance exchange: Workers can purchase health insurance from the exchange (the Connector). The premium is based on the entire pool of health insurance purchasers within each age group and does not depend on individual characteristics except for age.

3. Health insurance subsidies: Workers with incomes between 150 percent and 300 percent of the FPL receive subsidies when they purchase health insurance from the exchange. The health insurance premium is up to 2.7 percent of their income.

4. Medicaid expansion: Workers with incomes below 150 percent of the FPL receive free health insurance.

5. Employer mandate: Firms with 11 or more FTE employees have to offer health insurance to FT workers or pay a penalty of $\$ 295$ per full-time employee. 
6. Financing: $\tau_{w}$ and $\tau_{u}$ are adjusted to satisfy the respective government budget constraint.

Because we can implement only a stylized version the Massachusetts Health-Care Reform, let us mention four caveats. First, although Medicaid expansion in Massachusetts is targeted only for parents, children, and pregnant women, we assume that all individuals with incomes below 150 percent of the FPL become eligible for Medicaid under the reform. The ACA indeed expands Medicaid to all individuals, but Massachusetts reform did not. Therefore, the expansion of Medicaid as a result of the Massachusetts reform in the model is overstated, and the welfare effect of the Massachusetts reform is overestimated as well. Second, as with the case of the ACA, we do not implement that age restriction of the health insurance premium, because that would generate arbitrary cross-subsidization across different age groups. As we discussed, in the case of the ACA, the equilibrium health insurance premium in the model with the ACA turns out to be close to the 3:1 ceiling. Therefore, not implementing the age restriction is not a serious problem. However, in the case of the Massachusetts reform, the equilibrium health insurance premium exceeds the 2:1 ratio imposed by the actual reform. Third, we do not recalibrate the model to Massachusetts; in our experiments, we keep the same baseline model that is calibrated to the entire U.S. labor force. This makes the comparison between the ACA and the Massachusetts reform easier. However, the composition of different types of workers is different between the entire U.S. labor force and the labor force in Massachusetts, as can be seen in Tables 15 and 16. Finally, an important assumption is that the labor markets clear within Massachusetts in the model, which is unrealistic to some extent. In addition, some workers and firms move in or out of Massachusetts because of the reform, which is not captured by the model.

Table 17 compares the key statistics among the calibrated baseline model (first column), the model with the ACA (second column), and the model with the Massachusetts Health-Care Reform (third column). First, the Massachusetts reform achieves a lower uninsured rate (4.0 percent) than the ACA (5.4 percent), and the welfare gain is larger with the Massachusetts reform $(+0.60$ percent) than with the ACA $(+0.52$ percent). Because the health insurance subsidies are more generous and Medicaid is available for workers with even higher incomes than under the ACA, the proportion of workers obtaining Medicaid and subsidized PHI is higher under the Massachusetts reform. However, because the employer mandate penalty is lower, fewer firms offer health insurance and thus fewer workers obtain health insurance from their employers. Although the more generous nature of the Massachusetts reform requires a higher tax to finance the reform (2.2 percent in the Massachusetts reform versus 1.6 percent under the ACA), a more extensive redistribution through more generous health insurance subsidies leads to a higher welfare gain under the Massachusetts reform. 
Table 17: The ACA vs. the Massachusetts Health-Care Reform ${ }^{1}$

\begin{tabular}{lrrr}
\hline \hline & Baseline & The ACA & MA Reform \\
\hline Health Insurance Choices & & & \\
Employer health insurance (EHI) & 56.30 & 54.80 & 47.96 \\
Private health insurance (PHI) & 14.45 & 14.58 & 18.55 \\
Medicaid & 6.61 & 25.18 & 29.54 \\
Uninsured & 22.64 & 5.44 & 3.95 \\
\hline Labor Market Outcomes & & & \\
FT employed & 79.25 & 78.22 & 78.29 \\
PT employed & 15.11 & 16.42 & 16.34 \\
Unemployed & 5.64 & 5.36 & 5.37 \\
\hline Total hours worked & 20.19 & 20.12 & 20.12 \\
Output & 7.154 & 7.126 & 7.124 \\
$\tau_{w}(\%)$ & 0.80 & 1.64 & 2.16 \\
$\tau_{u}(\%)$ & 0.83 & 0.80 & 0.80 \\
\hline Welfare in CEV $(\%)$ & - & +0.52 & +0.60 \\
\hline \hline
\end{tabular}

${ }^{1}$ One PT worker is counted as 0.54 full-time equivalent. $\mathrm{CEV}=$ Consumption equivalent variation.

In terms of the labor market outcomes, the composition among FT employment, PT employment, and unemployment is similar under the two reforms. In both cases, workers are less attached to FT employment with health insurance. As a result, PT employment increases to about 16.4 percent under both reforms compared with 15.1 percent in the model without a reform.

How well does our model capture changes in Massachusetts in the post-reform period? In Section G.2, we compared labor market outcomes and insurance enrollment in Massachusetts in the pre- and post-reform periods. Table 17 shows that our model successfully captures the main features of the experience in Massachusetts: (i) the uninsured rate drops significantly after the implementation of the reform, (ii) which is mostly due to increased enrollment in Medicaid; (iii) the proportion of workers with PHI increases slightly; and (iv) the proportion of workers with EHI declines slightly. The model also predicts a shift in employment from FT to PT, which is consistent with the observed changes pre- and post-reform in Massachusetts, as we show in Section G.2. However, a part of the observed shift in the data might be due to the effect of the Great Recession; some workers might have unwillingly accepted PT jobs while FT jobs were relatively scarce. 
Table 18: Sensitivity Analysis ${ }^{1}$

\begin{tabular}{lrrrrrr}
\hline \hline & \multicolumn{2}{c}{ Baseline } & & \multicolumn{2}{c}{ Higher $\epsilon(4.3)$} \\
\cline { 2 - 3 } \cline { 6 - 7 } & No ACA & The ACA & & No ACA & The ACA \\
\hline EHI & 56.30 & 54.80 & & 56.28 & 53.44 \\
PHI & 14.45 & 14.58 & & 14.45 & 15.40 \\
Medicaid & 6.61 & 25.18 & & 6.63 & 25.94 \\
Uninsured & 22.64 & 5.44 & & 22.64 & 5.22 \\
\hline FT employed & 79.25 & 78.22 & & 79.18 & 76.27 \\
PT employed & 15.11 & 16.42 & & 15.18 & 18.39 \\
Unemployed & 5.64 & 5.36 & & 5.64 & 5.34 \\
\hline Total hours worked & 20.19 & 20.12 & & 20.18 & 19.91 \\
Welfare in CEV (\%) & - & +0.54 & & - & +0.78 \\
\hline \hline
\end{tabular}

${ }^{1}$ Percentage of the total labor force. $\mathrm{CEV}=$ Consumption equivalent variation.

\section{H Sensitivity Analysis}

To investigate sensitivity of the main results - effects of the ACA on the labor market, we revisit the effects of introducing the ACA with a higher elasticity of substitution between FT and PT workers. We use an elasticity of 2.0 for our baseline experiment, following Mulligan (2014), but there is a wide range of estimates available. For example, Montgomery and Cosgrove (1993) use data of a cross-section of firms and estimate a range of 1.7 to 2.6 for the elasticity of substitution in production between FT and PT workers. On the other hand, Owen (1979) obtains a point estimate of 4.3 using aggregate data. We use the elasticity of 4.3 for our sensitivity analysis to obtain a reasonable maximum response of the FT and PT allocation to the ACA. Table 18 summarizes the results, by comparing the baseline results (columns 1-2) with the results in the model with a higher elasticity of substitution (columns $3-4)$. We recalibrate the model with $\epsilon=4.3$ so that the model replicates the same set of targets as the baseline model economy. Most important, the response of hours is stronger in the model with a higher elasticity. The proportion of PT workers increases from 15.2 percent to 18.4 percent (5.0 million increase in PT employment), while it increases to 16.4 percent in the baseline model. The negative effect to total hours is also larger, at 1.3 percent, compared with 0.36 percent in the baseline. The uninsured rate declines a bit more, to 5.2 percent (compared with 5.4 percent in the baseline), and the welfare gain from the ACA is slightly larger, at 0.78 percent of flow consumption, compared with 0.54 percent in the baseline experiment. 


\section{References}

Aizawa, Naoki and Hanming Fang, "Equilibrium Labor Market Search and Health Insurance Reform," NBER Working Paper, 2013.

Becker, Thealexa and Didem Tüzemen, "Self-Employment and Health Care Reform: Evidence from Massachusetts," FRB Kansas City Research Working Paper RWP 14-16, 2015.

Boedo, Hernan J. Moscoso and Toshihiko Mukoyama, "Evaluating the Effects of Entry Regulations and Firing Costs on International Income Differences," Journal of Economic Growth, 2012, 17 (2), 143-170.

Brügemann, Björn and Iourii Manovskii, "Fragility: A Quantitative Analysis of the U.S. Health Insurance System," Working paper, 2010.

Conesa, Juan Carlos, Sagiri Kitao, and Dirk Krueger, "Taxing Capital? Not a Bad Idea After All!," American Economic Review, 2009, 99 (1), 25-48.

Congressional Budget Office, "The Budget and Economic Outlook: 2014-2024," February 2014 .

Even, William E. and David A. Macpherson, "The Affordable Care Act and the Growth of Involuntary Part-Time Employment," Working paper, 2015.

Fang, Hanming and Andrew Shephard, "Joint Household Labor Supply and Health Care Reform," Working paper, 2015.

Feng, Zhigang, "Macroeconomic Consequences of Alternative Reforms to the Health Insurance System in the U.S.," Working paper, 2012.

- and Kai Zhao, "Employment-Based Health Insurance, Uncertain Medical Expenses, and Aggregate Labor Supply," Working paper, 2014.

Gallen, Trevor S. and Casey B. Mulligan, "Wedges, Labor Market Behavior, and Health Insurance Coverage under the Affordable Care Act," Working paper, 2013.

Garthwaite, Craig, Tal Gross, and Matthew Notowidigdo, "Public Health Insurance, Labor Supply, and Employment Lock," Quarterly Journal of Economics, 2014, 129 (2).

Government Accountability Office, "Small Employer Health Tax Credit: Factors Contributing to Low Use and Complexity," 2012, GAO-12-549. 
Güner, Nezih, Gustavo Ventura, and Xu Yi, "Macroeconomic Implications of SizeDependent Policies," Review of Economic Dynamics, 2008, 11, 721-744.

Hackmann, Martin B., Jonathan T. Kolstad, and Amanda E. Kowalski, "Adverse Selection and an Individual Mandate: When Theory Meets Practice," American Economic Review, 2015, 105 (3), 1030-1066.

Hansen, Gary D., Minchung Hsu, and Junsang Lee, "Health Insurance Reform: The Impact of a Medicare Buy-In," Journal of Economic Dynamics and Control, 2014, 45, $315-329$.

Hopenhayn, Hugo and Richard Rogerson, "Job Turnover and Policy Evaluation: A General Equilibrium Analysis," Journal of Political Economy, 1993, 101 (5), 915-938.

Hubbard, R. Glenn, Jonathen Skinner, and Stephen P. Zeldes, "Precautionary Saving and Social Insurance," Journal of Political Economy, 1995, 103 (2), 360-399.

Janicki, Hubert, "Distributional Effects of Public Health Insurance Reform," Working paper, 2011.

Jeske, Karsten and Sagiri Kitao, "U.S. Tax Policy and Health Insurance Demand: Can a Regressive Policy Improve Welfare?," Journal of Monetary Economics, 2009, 56 (2), 210-221.

Jung, Juergen and Chung Tran, "Market Inefficiency, Insurance Mandate and Welfare: U.S. Health Care Reform 2010," Review of Economic Dynamics, 2016, 20, 132-159.

Kaiser Family Foundation and Health Research and Educational Trust, "Employer Health Benefits: Annual Survey," 2004-2006.

Kolstad, Jonathan T. and Amanda E. Kowalski, "Mandate-Based Health Reform and the Labor Market: Evidence from the Massachusetts Reform," Journal of Health Economics, 2016, 47, 81-106.

Lee, Jason, "Are Health Insurance Premiums Higher for Small Firms?," Research Synthesis Report No. 2, 2002.

Montgomery, Mark and James Cosgrove, "The Effect of Employee Benefits on the Demand for Part-Time Workers," Industrial and Labor Relations Review, 1993, 47 (1), $87-98$. 
Mulligan, Casey B., "The Affordable Care Act and the New Economics of Part-Time Work," Mercatus Working Paper, 2014.

Mulligan, Casey B, Side Effects and Complications: The Economic Consequences of Health-Care Reform, University of Chicago Press, 2015.

Nakajima, Makoto, "A Quantitative Analysis of Unemployment Benefit Extensions," Journal of Monetary Economics, 2012, 59 (7), 686-702.

Owen, John D., Working Hours: An Econometric Analysis, Lexington, MA: Lexington Books, 1979.

Pashchenko, Svetlana and Ponpoje Porapakkarm, "Quantitative Analysis of Health Insurance Reform: Separating Regulation from Redistribution," Review of Economic Dynamics, 2013, 16, 383-404.

Restuccia, Diego and Richard Rogerson, "Policy Distortions and Aggregate Productivity with Heterogeneous Plants," Review of Economic Dynamics, 2008, 11, 707-720.

Shimer, Robert, "The Cyclical Behavior of Equilibrium Unemployment and Vacancies," American Economic Review, 2005, 95 (1), 25-49.

Tauchen, George, "Finite State Markov-Chain Approximations to Univariate and Vector Autoregressions," Economic Inquiry, 1986, 20 (2), 177-181. 